\title{
Tectonics
}

\author{
RESEARCH ARTICLE \\ 10.1029/2019TC005894 \\ Key Points: \\ - Intermediate depth seismicity is \\ controlled by bending in a wide \\ range of settings \\ - Geometric differences lead to \\ contrasting seismic expression \\ between the east and west Pacific \\ - Double seismic zones associated \\ with bending are often masked by \\ the strong temperature controls on \\ seismicity
}

Supporting Information:

- Supporting Information S1

Correspondence to:

D. Sandiford,

dan.sandiford@utas.edu.au

Citation:

Sandiford, D., Moresi, L. M.,

Sandiford, M., Farrington, R., \&

Yang, T. (2020). The fingerprints of

flexure in slab seismicity. Tectonics, 39 , e2019TC005894. https://doi.org/

10.1029/2019TC005894

Received 21 SEP 2019

Accepted 14 JUN 2020

Accepted article online 22 JUN 2020

(C)2020. American Geophysical Union. All Rights Reserved.

\section{The Fingerprints of Flexure in Slab Seismicity}

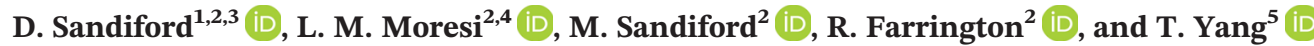 \\ ${ }^{1}$ Institute of Marine and Antarctic Studies, University of Tasmania, Hobart, Tasmania, Australia, ${ }^{2}$ School of Earth \\ Sciences, University of Melbourne, Melbourne, Victoria, Australia, ${ }^{3}$ Helmholtz Centre Potsdam - German Research \\ Centre for Geosciences (GFZ), Potsdam, Germany, ${ }^{4}$ Research School of Earth Sciences, Australian National University, \\ Canberra, Australian Capital Territory, Australia, ${ }^{5}$ Department of Earth and Space Sciences, Southern University of \\ Science and Technology, Shenzhen, China
}

\begin{abstract}
Earthquake moment tensors in eastern Pacific (ePac) slabs typically show downdip tensional (DT) axes, whereas in the western Pacific (wPac), they typically show downdip compressional (DC) axes or have mixed orientations indicative of unbending. Prevailing conceptual models emphasize uniform stress/deformation modes, that is, bulk slab stretching or shortening, as the dominant control on intermediate depth seismic expression. In contrast, we propose that a diversity of seismic expression, including DT- and DC-dominated regions, is consistent with expectations of flexural strain accumulation, based on systemic differences in slab geometry. Our analysis reveals two largely unrecognized features of ePac intraslab seismicity. First, earthquake clusters consistent with slab unbending are present in ePac slabs, albeit at much shallower depths than typical of wPac slabs. Second, intermediate depth ePac DT seismicity is strongly localized to the upper half of zones undergoing curvature increase, such as flat slab segments. Our study highlights how the seismic expression of slab flexure is impacted by the relative contribution of brittle and ductile deformation. The strongly asymmetric temperature structure that is preserved in sinking slabs means that seismicity disproportionately records the deformation regime in the colder part of the slab, above the neutral plane of bending. The expression of in-plane stress may be discernible in terms of a systematic modifying effect on the seismic expression of flexure.
\end{abstract}

\section{Introduction}

Inclined zones of earthquakes extending to depths of up to $700 \mathrm{~km}$ beneath volcanic arcs delineate the geometry of subducting slabs and provide a unique insight into plate tectonics and mantle convection (e.g., Elsasser, 1969; McKenzie, 1969). To the extent that rupture mechanisms of these subduction related earthquakes are thought to reflect the force balance in subducting slabs, they have been used to provide key insights into the basic mechanisms of plate tectonics. The force system in slabs includes buoyancy forces due to thermal and metamorphic density contrasts, flexural stress associated with slab bending and unbending, and resistance arising from slip along the subduction interface and deeper mantle penetration (e.g., Fujita \& Kanamori, 1981; House \& Jacob, 1982; Isacks \& Molnar, 1971; Sleep, 1979).

Intermediate depth earthquakes have traditionally been defined as those in the approximately 70- to $300-\mathrm{km}$ depth range, where the subducting slab is mainly detached from the overriding plate (Gutenberg \& Richter, 1954). The classic studies of (Isacks \& Molnar, 1969; 1971) showed that either the least or most extensive moment tensor eigenvectors tend to be aligned in the slab downdip direction, consistent with the slab acting as a stress guide in a weaker mantle (Figures 1d and 1h, Elsasser, 1969). They also identified that the coseismic deformation patterns at intermediate depths correlate with broader seismic distribution in the slab. Slabs segments with no deep earthquakes, or significant gaps between intermediate and deep earthquakes, usually exhibit downdip tension/stretching referenced herein as "DT" (Figure 1h). In contrast, slabs with deep and continuous seismicity tend to be dominated by downdip compression/shortening, referenced as "DC" (Figure 1d). Based on these spatial relationships, Isacks and Molnar (1971) helped to establish the prevailing paradigm that slab earthquake orientations mainly reflect a uniaxial, or uniform, deformation mode in the slab reference frame. The enduring nature of these insights is exemplified in a quote from a recent study, "slabs seem to be stretching as gravity acting on excess mass in the slabs pulls them down, like dangling springs hanging from and attached to lithosphere above" (Molnar \& Bendick, 2019). 

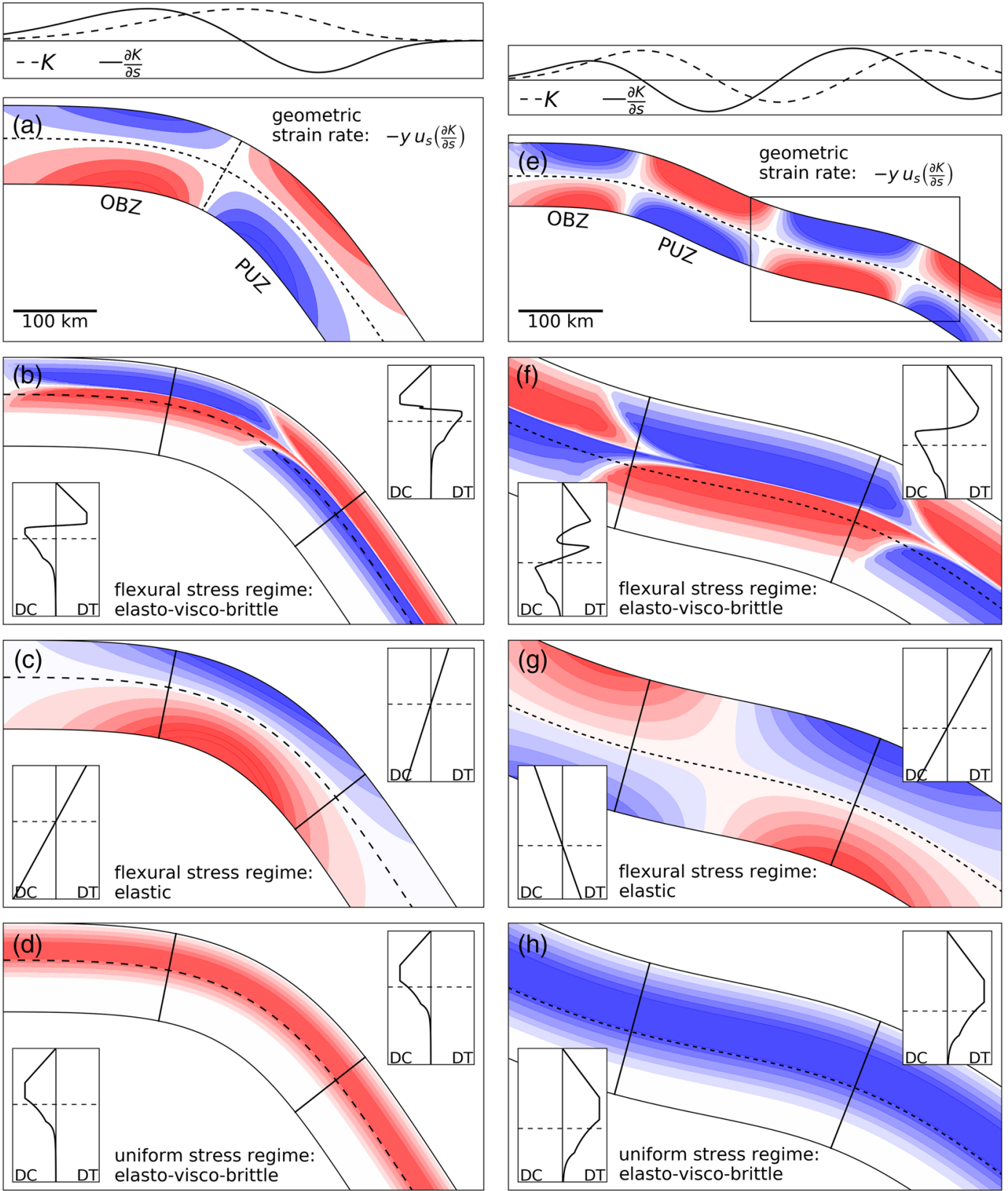

Figure 1. Schematic illustration of key geometrical/mechanical concepts motivating our analysis of the seismic expression of subducting slabs. Left side: typical west Pacific style subduction geometry as represented for example by Tonga. Right side: typical eastern Pacific style subduction geometry as represented for example by Chile. (a and e) Top panel: slab midplane curvature (dashed) and curvature gradient (solid). (a and e) Bottom panel: geometric strain rate. Box in (e) shows areas enlarged in (f)-(h). (b and f) Stress distribution for a elasto-plasto-viscous rheology deforming by geometric bending. (c and g) Stress distribution for a purely elastic rheology deforming by geometric bending. ( $\mathrm{d}$ and $\mathrm{h}$ ) Stress distribution for for a elasto-visco-plastic rheology deforming in response to uniform downdip compression (left) and extension (right). Insets show schematic differential stress profiles across the slab, as marked by solid black line with positive values implying extension.

The correlations identified by Isacks and Molnar (1971), which relate to the seismicity patterns in individual slab segments, also expose contrasts between eastern Pacific (ePac) slabs and western Pacific (wPac) slabs. In ePac slabs such as Chile, intermediate depth focal mechanisms are strongly dominated by DT earthquakes, whereas wPac slabs such as Tonga tend to be dominated by DC events. DT regimes are often attributed to 
uniform stretching due to slab pull (Bailey et al., 2009; Bloch et al., 2018; Isacks \& Molnar, 1971; Rietbrock \& Waldhauser, 2004), while DC regimes have been attributed to the propagation of compressional stress along the slab from interactions between the deep parts of the slab and the transition zone (Figures $1 \mathrm{~d}$ and $1 \mathrm{~h}$ Billen et al., 2003; Fujita \& Kanamori, 1981; Gurnis et al., 2000).

In detail, it has long been recognized that slab seismicity patterns are more complex than either strictly DC or DT, leading to the proposition that other deformation modes such as flexure are expressed in some slabs, e.g. northern Japan, Kuriles, Tonga, northern Marianas, and eastern Aleutians. In these cases, intermediate depth focal mechanisms exhibit a systematic polarity switch, suggesting that while the upper part of the slab is in DC, the lower part is in DT (Engdahl \& Scholz, 1977; Hasegawa et al., 1978; Kawakatsu, 1986b; 1986a; Kita et al., 2010; Samowitz \& Forsyth, 1981; Sleep, 1979; Tsukahara, 1980; Wang, 2002). Such double seismic zones (DSZs) are consistent with unbending in the presence of dehydration embrittlement.

However, because some DSZs continue beyond the expected depths of unbending and others have an opposite polarity to that expected from slab unbending (Comte et al., 1999), additional sources of stress have been argued to play a significant role in localizing DSZ seismicity (Brudzinski et al., 2007; Fujita \& Kanamori, 1981). Some studies have focused on DSZs as an expression of metamorphic/dehydration phenomena, often without explicit consideration of the associated rupture mechanisms or sources of deviatoric stress (e.g., Peacock, 2001). Indeed, metamorphic and fluid processes have long been seen as key to intermediate depth earthquake nucleation (e.g., Isacks \& Molnar, 1971) and have dominated discussions of slab seismicity in recent decades (Chen et al., 2019; Faccenda, 2014; Green \& Houston, 1995; Hacker et al., 2003; Kirby et al., 2013; Peacock, 2001; Seno \& Yamanaka, 2013; Tsujimori et al., 2006).

Even allowing for the strong weakening role played by dehydration, the concept that some slabs undergo appreciable rates of stretching $\left(10^{-15} \mathrm{~s}^{-1}\right.$, e.g., Kawakatsu, 1986a) implies high deviatoric stresses. This is because uniform stretching involves not only the deformation of a shallow, brittle part of the slab but also the deeper, ductile slab core (e.g., Capitanio et al., 2009). Conrad and Lithgow-Bertelloni (2004) argued that in order to produce bulk stretching rates in the order of $10^{-15} \mathrm{~s}^{-1}$, the effective tensional stress magnitudes may be as much as $500 \mathrm{MPa}$, assuming effective slab viscosity several hundred times higher than typical upper mantle. While uncertainties in slab rheology mean such stress estimates are speculative, they are not implausible given the thermal and compositional buoyancy forces in subducting slabs are of order $10^{13} \mathrm{~N} \mathrm{~m}^{-1}$.

In this study, we argue that strain accompanying geometric bending (Figures 1a and 1e) provides an important control on the seismic moment release in many Pacific margin slab settings, albeit in ways that are subtly obscured by the rheological transition from brittle to ductile deformation. We show, firstly, that earthquakes due to slab unbending are much more widespread than previously recognized, occurring in both ePac as well as wPac slabs. An important difference is that in ePac slabs the unbending takes place at much shallower depths than in wPac slabs. Hence, most ePac unbending earthquakes have strong spatial overlap with the megathrust zone and so have been largely overlooked in previous analyses. In section 2, we describe a procedure to filter megathrust earthquakes from global catalogs, which helps reveal the characteristic ePac shallow unbending signature.

We also show that ePac intermediate depth seismicity is conspicuously clustered in the upper parts of curvature-increasing zones associated with full or partial slab flattening. In such zones, we speculate that seismicity is mainly restricted to the cold, upper half of the slabs, where they evidence downdip stretching, and that the associated shortening in the lower half of the slab is largely accommodated aseismically. Crucially, while the larger earthquakes reported in the global catalogs tend to show uniform intermediate depth DT seismicity, microseismic studies in Chile have revealed oppositely polarized DSZs (Comte \& Suarez, 1994), consistent with flexure. For geometric bending to be expressed so prominently, strain rates associated with flexure (Figures $1 \mathrm{~b}$ and $1 \mathrm{f}$ ) must be comparable to, or exceed, those associated with uniform stretching modes due to, for example, slab pull (Figures $1 \mathrm{~d}$ and $1 \mathrm{~h}$ ). This is consistent with the notion that slab buoyancy is largely supported by drag in the upper mantle. Variations in the uncompensated slab pull component will impact the relative location of the bending neutral plane with respect to the brittle ductile transition. This effect can have a strong impact on seismic expression, variously enhancing or impeding seismicity beneath the neutral plane. 


\section{Terminology, Methods, and Manuscript Structure}

In seismology, the term "intermediate depth" typically refers to subduction related earthquakes with hypocentral depths in the range of $70-300 \mathrm{~km}$. We argue that the restriction to events deeper than about $70 \mathrm{~km}$ has imposed somewhat arbitrary limitations on analyses of subduction related seismicity. Here, we use the term "slab" or "intraslab" earthquakes to refer to all earthquakes within the subducting lithosphere from the onset of bending near the outer rise to the deepest limit of seismicity at $\sim 700 \mathrm{~km}$. However, our analysis focuses only on earthquakes shallower than $300 \mathrm{~km}$. This is because uncertainties in slab geometry as well as earthquake hypocenters increase with depth. In addition, slab earthquake activity rates are typically very low at depths of around $300 \mathrm{~km}$ (e.g., Vassiliou et al., 1984). As a consequence, our methods are not well suited to depths beyond a few hundred kilometers. Importantly, we assume no intrinsic distinction between earthquakes with hypocentral depths above and below $70 \mathrm{~km}$. We still occasionally refer to the intermediate depth range, as this remains a familiar specification of a particular depth range.

We also consider the term "outer rise" earthquakes is something of a misnomer because earthquakes that result from the bending of the incoming plate are concentrated in the outer trench slope and often extend landward of the trench to regions of the slab beneath the shallow part of the forearc. Hence, we will refer to the region where the incoming plate experiences increasing curvature as the "outer bending zone" (or OBZ). Downdip of the OBZ, after passing through peak curvature, slabs invariably straighten in a zone of unbending which we term the primary unbending zone (or PUZ). These regions are labeled in Figure 1a.

In discussing contributions to the slab deformation rate, we emphasize the distinction between flexural and uniform modes (see Figure 1). We use the terms flexure and bending somewhat interchangeably, in keeping with historical developments in the literature. Flexural strain is associated with changes in curvature. Curvature is considered positive when the slab curvature is concave down. Material may respond to a change in curvature in a number of ways, for instance by simple bending, or by flexural slip. While flexural slip has been discussed in relation to slab seismicity (Romeo \& Álvarez-Gómez, 2018), our study focuses on simple bending, in which cross sections orthogonal to the plate are assumed to remain planar. In this case, the total strain is proportional to the curvature and is characterized by antisymmetry across the neutral plane. Regions where curvature is increasing, for example, are associated with downdip extension above and compression below the neutral plane. Arguments that bending/unbending is a controlling factor stem primarily from the observation polarity switches in earthquake moment tensors in DSZs. In contrast, for a "uniform" mode of slab deformation, involving either bulk slab stretching or shortening in the downdip direction, such polarity switches are precluded.

Strain rates associated with changes in curvature can be separated into a time-dependent and advective component. Where the morphology of the slab is changing in time, for instance a reduction in the curvature radius associated with slab steepening, there is a time-dependent component of the curvature rate. However, even if the morphology is stationary, bending still occurs where material passes through finite curvature gradients. This component of the curvature rate is often referred to as advective (Buffett \& Becker, 2012; Ribe, 2010) or kinematic (e.g., Kawakatsu, 1986a). Here, we use the term "geometric bending" to emphasize the association between the bending rate and the downdip curvature gradient.

It is important to note that bending is a description of strain and implies no specific constitutive behavior. In particular, the reader should be wary of thinking in terms of elastic sheet mechanics. If slabs behaved as perfectly elastic sheets, stress would vary systematically with the total curvature (e.g., Figures 1c and 1g), and in the process of unbending, the plate would simply return to an undisturbed elastic state. The occurrence of intermediate depth seismicity, along with a range of other observations, provides a strong argument that this is not the case (Billen et al., 2003; Chapple \& Forsyth, 1979; Goetze \& Evans, 1979; Sleep, 2012).

In describing the relationships between between slab geometry and seismicity, we refer frequently to the slab midplane. We use this term in relation to both observed slab geometries (sections 3 and 5) and the analysis of a numerical model (section 4). The notion of a midplane serves as a proxy for the neutral plane of bending, which plays a key role in determining the way deformation responds to changes in curvature. The estimation and applicability of the midplane is discussed in more detail in the supporting information S1.

The term "seismic expression" refers to the spatial distribution of hypocenters along with the associated moment tensors. The signature of flexural and uniform dynamic modes is very different (e.g., Figure 1), 
and we would expect the seismic expression to reflect this to some degree. In addition to the dynamic state of the slab, the seismic expression is obviously very dependant on the relative contribution of brittle and ductile deformation.

Our analysis primarily focuses on relationships between earthquake data and slab geometry, and so is limited by uncertainties in both. A detailed outline of our methods is provided in the supporting information S1, which covers our treatment of earthquake data, and numerical methods. We combine the global CMT (Ekström et al., 2012) and ISC-EHB (Engdahl et al., 1998) catalogs, to improve depth uncertainties and relate them using the either the Slab1 (Hayes et al., 2012) or Slab2 (Hayes et al., 2018) models, as discussed in the supporting information S1. A novel step is our filtering of shallow intraslab earthquakes from those on the subduction interface, as briefly described below.

"Megathrust" earthquakes on the subduction interface constitute a very significant proportion of the overall seismic activity in the shallow part of subduction zones. Although megathrust seismicity does not overlap spatially with intermediate depth earthquakes sensu stricto $(>70 \mathrm{~km})$, filtering of potential megathrust events is extremely important in terms of identifying intraslab seismicity at shallow depths beneath the forearc wedge. Even with comparatively accurate ISC-EHB depths, we cannot unambiguously discriminate intraslab from megathrust events on hypocenter data alone. The filtering procedure we use defines the strike and rake of the reference megathrust rupture tensor $\left(\mathbf{M}^{\text {ref }}\right)$, assuming a pure double-couple mechanism. A similarity condition $(\chi)$ for a given earthquake with $\left(\mathbf{M}^{k}\right)$ is referenced to the tensor dot product (:) of the normalized moment tensors:

$$
\chi=\left[\frac{\mathbf{M}_{i j}^{\mathrm{ref}}: \mathbf{M}_{i j}^{k}}{\left|\mathbf{M}^{\mathrm{ref}}\right|\left|\mathbf{M}^{k}\right|}\right]
$$

We assume an event is a megathrust rupture if it has a hypocentral depth less than $70 \mathrm{~km}$ and is within 20 $\mathrm{km}$ of the relevant slab surface model and a similarity condition of $\chi \geq 0.75$. Further details are provided in the supporting information S1.

The manuscript is structured as follows. Section 3 provides a summary of the seismic expression and morphology of representative Pacific margin slab sections, highlighting key features that motivate our analysis. Section 4 summarizes insights of slab dynamics drawn from a numerical subduction model in which flexural modes dominate the strain rate field. Drawing on the modeling insights, section 5 revisits the observations presented in section 3 to examine the specific relation between seismicity and curvature gradients needed to assess the role played by geometric bending. In section 6, we summarize the main findings and explore some of the broader issues that stem from them.

\section{Comparative Seismology and Geometry of the Pacific Slabs}

In this section, we compare three wPac slab segments (Figure 2) in Tonga, Japan, and the Kuriles and three ePac slab segments (Figure 4) in Chile, Peru, and Central America, using trench perpendicular transects to provide a regional overview of both slab geometry and seismicity. While deep $(>300 \mathrm{~km})$ seismicity is portrayed in some of the accompanying figures, our analysis is restricted to earthquakes shallower than 300 km. In our representations (e.g., Figure 2a), colored points show earthquakes designated as intraslab events, while earthquakes that lie more that $20 \mathrm{~km}$ above the projected slab surface, in the slab normal direction, are shown as small black points. Because the along-strike slab morphology tends to more variability with depth, the deviation in hypocenters from a "region-average" slab geometry increases with depth. This accounts, for instance, for the large number of outliers in Tonga at depths $>300 \mathrm{~km}$. However, the "region-average" slab geometries generally provide a consistent fit to slab seismicity at depths less than $300 \mathrm{~km}$ for most of the regions described here. There are some complexities in the case of the ePac slabs, discussed in more detail later.

We represent the orientation of slab earthquake moment tensors by projecting the $T$-axis onto trench-perpendicular vertical sections (e.g., Figure 3). The $T$-axis projections are not scaled by magnitude, so their projected length reflects the difference in azimuth of moment tensor eigenvectors with respect to the trench normal direction. We note $T$-axes necessarily lie within the quadrant with the smallest stress 

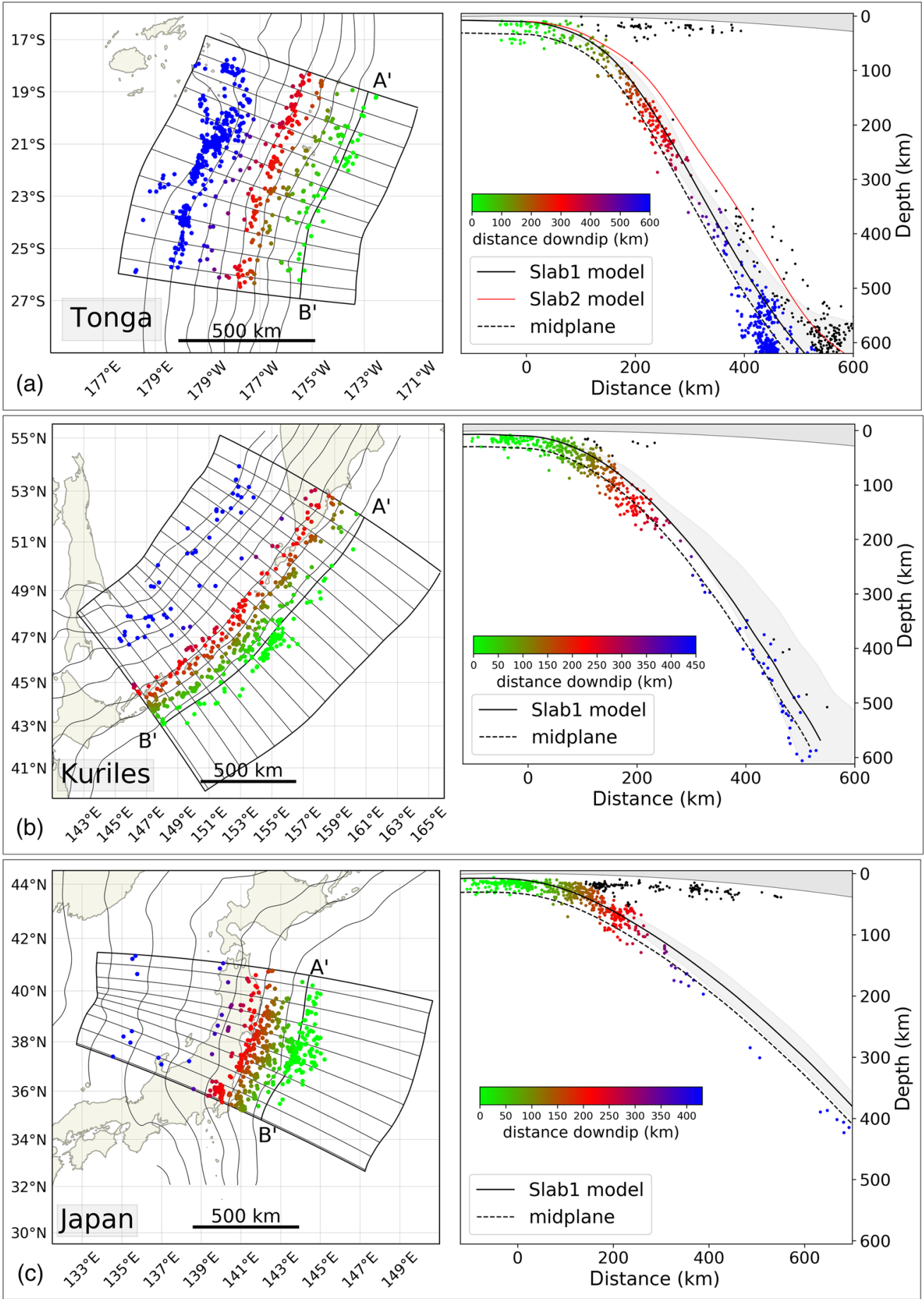

Figure 2. Overview of western Pacific margin slab segments analyzed in this study: (a) Tonga; (b) Kuriles; (c) Japan. Colored points show intraslab seismicity which is consistent with best available slab geometry model (e.g., Slab1 for wPac slabs). Earthquakes lying more than $20 \mathrm{~km}$ above the slab surface, shown as small black points, are considered upper plate events, outliers (presumably due to depth error), or regions where our slab models do not properly resolve the local slab morphology, and so along with earthquakes identified as likely megathrust ruptures (not shown) are excluded from our analysis. Left hand panels show slab earthquakes in map view. Right hand panels shows projection of the earthquakes on a trench-parallel cross section: the solid black line shows the region-averaged slab surface model; the gray region shows the lateral variation in slab surface model across the domain; the dashed black line shows the slab midplane (an orthogonal translation of the slab surface, as discussed in the supporting information S1); the red dashed line shows the Slab2 model for Tonga, which shows less consistency with the earthquake hypocenters (ISC-EHB catalog). 

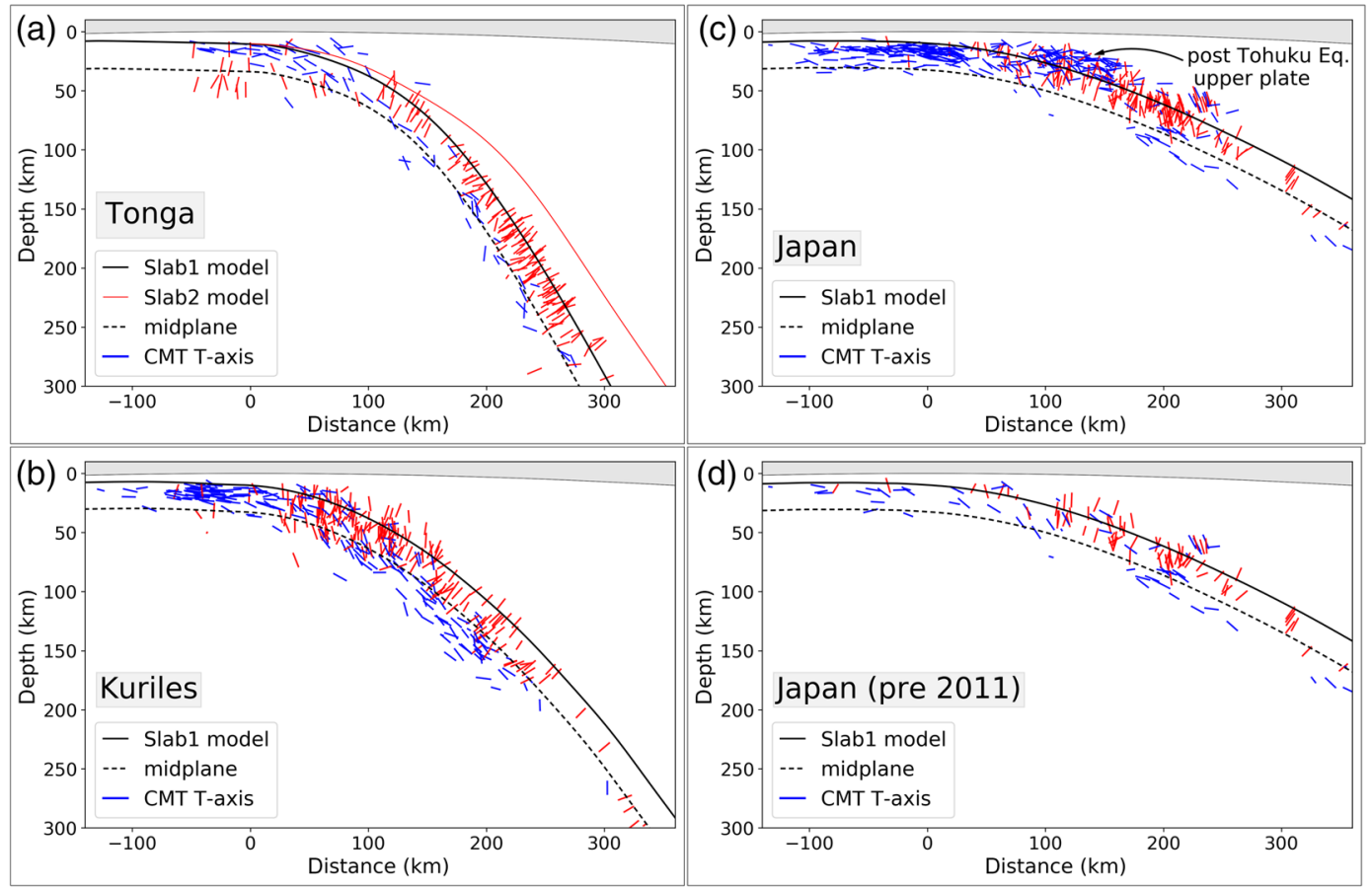

Figure 3. wPac trench-perpendicular projection of CMT T-axes (ISC-EHB hypocenters) on a vertical cross sections, along the nearest trench normal azimuthal lines shown Figure 2, with data aggregated across the entire domain: (a) Tonga; (b) Kuriles; (c) Japan; (d) Japan showing events prior to 2011. The origin of the horizontal axis represents the trench location. The $T$-axes are plotted as projections of uniform-length vectors, with the length variation in the plotted $T$-axes reflecting the magnitude of the projected component of the vector. $T$-axes are colored according to the orientation relative to the slab midplane (shown with dashed black line): red represents earthquakes with a DC sense, blue with a DT sense.

eigenvector and are commonly assumed to represent the orientation of most extensive coseismic strain release (Bailey et al., 2009; Isacks \& Molnar, 1971; Yang et al., 2017). The color of the T-axes represents the angle relative to the local slab orientation. Red colors are DC events; blue are DT events.

Seismicity associated with the OBZ is clearly evident in each of the wPac regions, with the onset of characteristic normal faulting events at distances of around $50 \mathrm{~km}$ seaward of the trench in Tonga and $100 \mathrm{~km}$ in Japan and the Kuriles. In all cases, this DT seismicity appears to continue, in a largely continuous manner, landward of the trench, up to about $50 \mathrm{~km}$ in the case of Tonga. As discussed later, this suggests that the curvature of the slab continues to increase downdip from the trench. This morphological property is corroborated in the Slab1 model, which represents a surface fit to the seismicity (discussed in more detail in section 5). Yet it runs counter to typical models of elastic or elastic-plastic plate flexure (Caldwell et al., 1976), where unbending occurs before the trench, even when the influence of yielding is carefully considered (Chapple \& Forsyth, 1979). Deeper DC events in the OBZ are generally viewed having a reciprocal flexural origin to DT ones, reflecting shortening beneath the neutral plane (Chapple \& Forsyth, 1979; Craig et al., 2014). Based on the data sets used in this study, only Tonga exhibits an unambiguous record of deep DC events in the OBZ. The onset of these events is virtually coincident with the shallower DT events, at around $50 \mathrm{~km}$ from the trench. In the Kuriles and Japan, the number of potential DC events is very low compared with the OBZ normal faulting events. Nevertheless, DC OBZ events are documented in both regions (Craig et al., 2014), as evidenced by a recent (25 March 2020) Mw 7.5 earthquake, with a hypocenter at 55-km depth located almost directly under the Kuriles trench (depth based on USGS finite fault model).

Historically, the role of unbending in slab seismicity has mainly been discussed in relation to the Kuriles, Japan, Tonga, Aleutians, and northern Marianas (Engdahl \& Scholz, 1977; Hasegawa et al., 1978; Kawakatsu, 1986b; 1986a; Samowitz \& Forsyth, 1981; Tsukahara, 1980; Wang, 2002). The key feature of these regions is the DSZs with a characteristic "polarity" switch in moment tensor between an upper band dominated by DC events and a lower band dominated by DT events. This distribution is very clear in the 

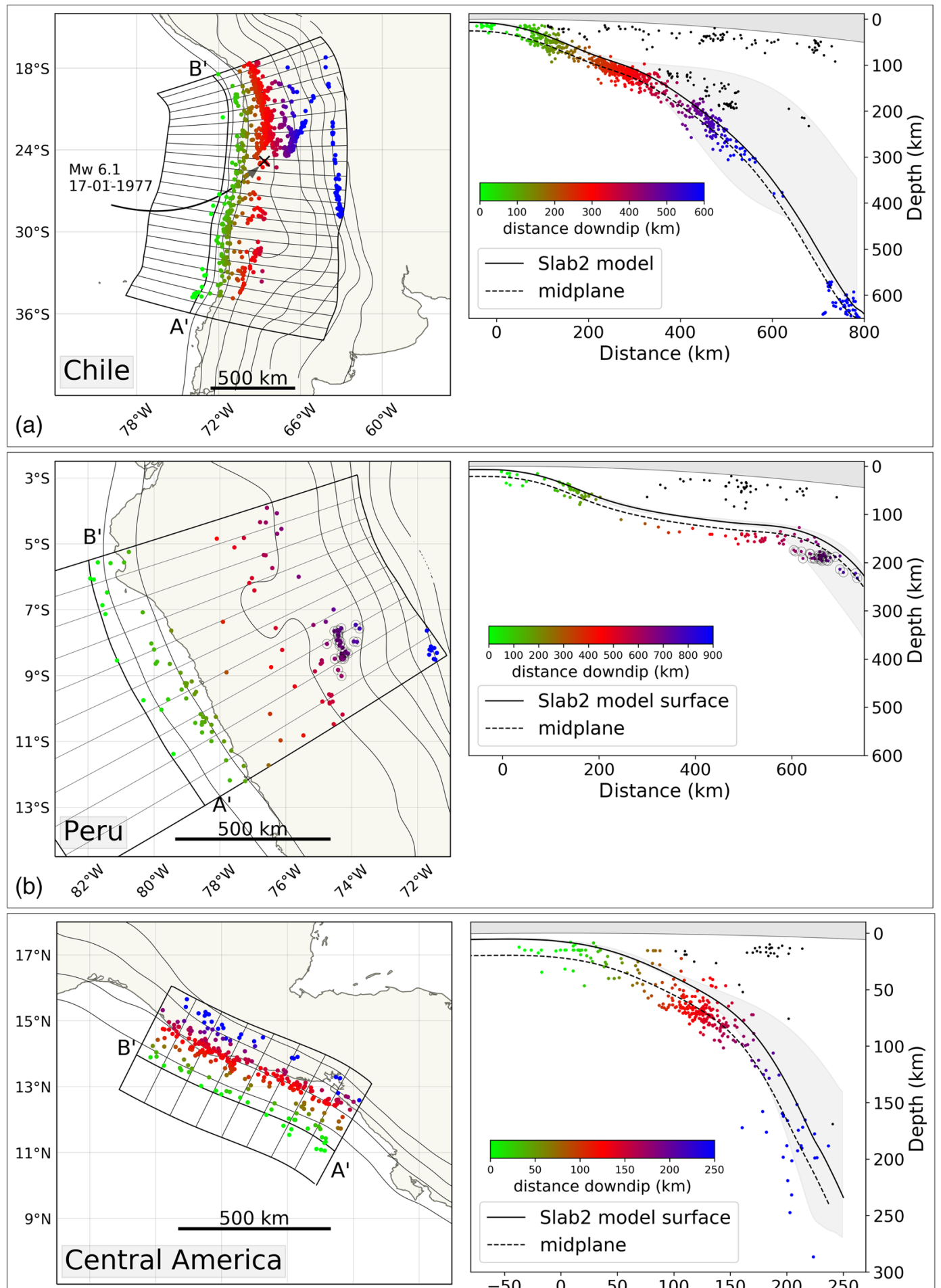

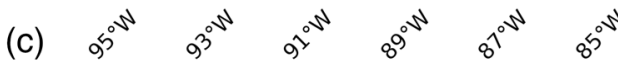

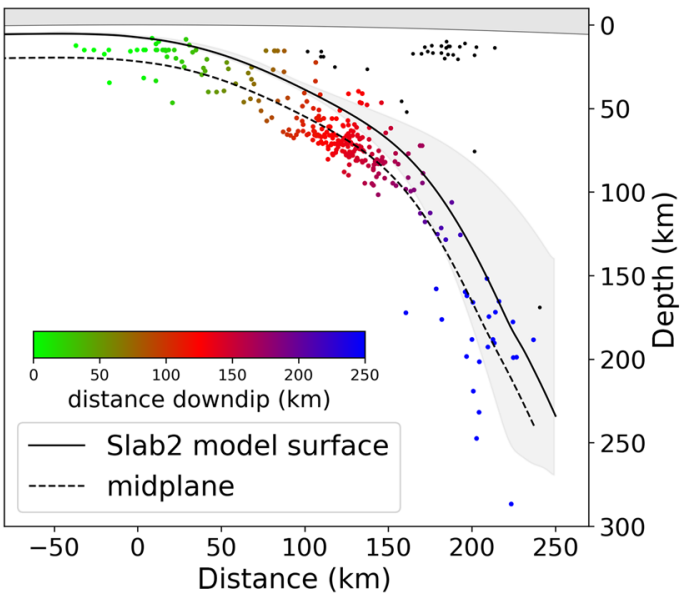

Figure 4. Overview of eastern Pacific margin slab segments analyzed in this study: (a) Chile; (b) Peru; (c) Central America See Figure 2 caption for details of figure organization and preparation. The black points represent earthquakes that lie more the $20 \mathrm{~km}$ above the slab surface model. For Chile, these mainly represent the relatively small number of earthquakes that occur in close proximity to the Pampean flat slab in the south, where the slab morphology is quite different to northern Chile. In (b), the Pucallpa Nest earthquakes are indicated by open circles (as discussed in the main text). 

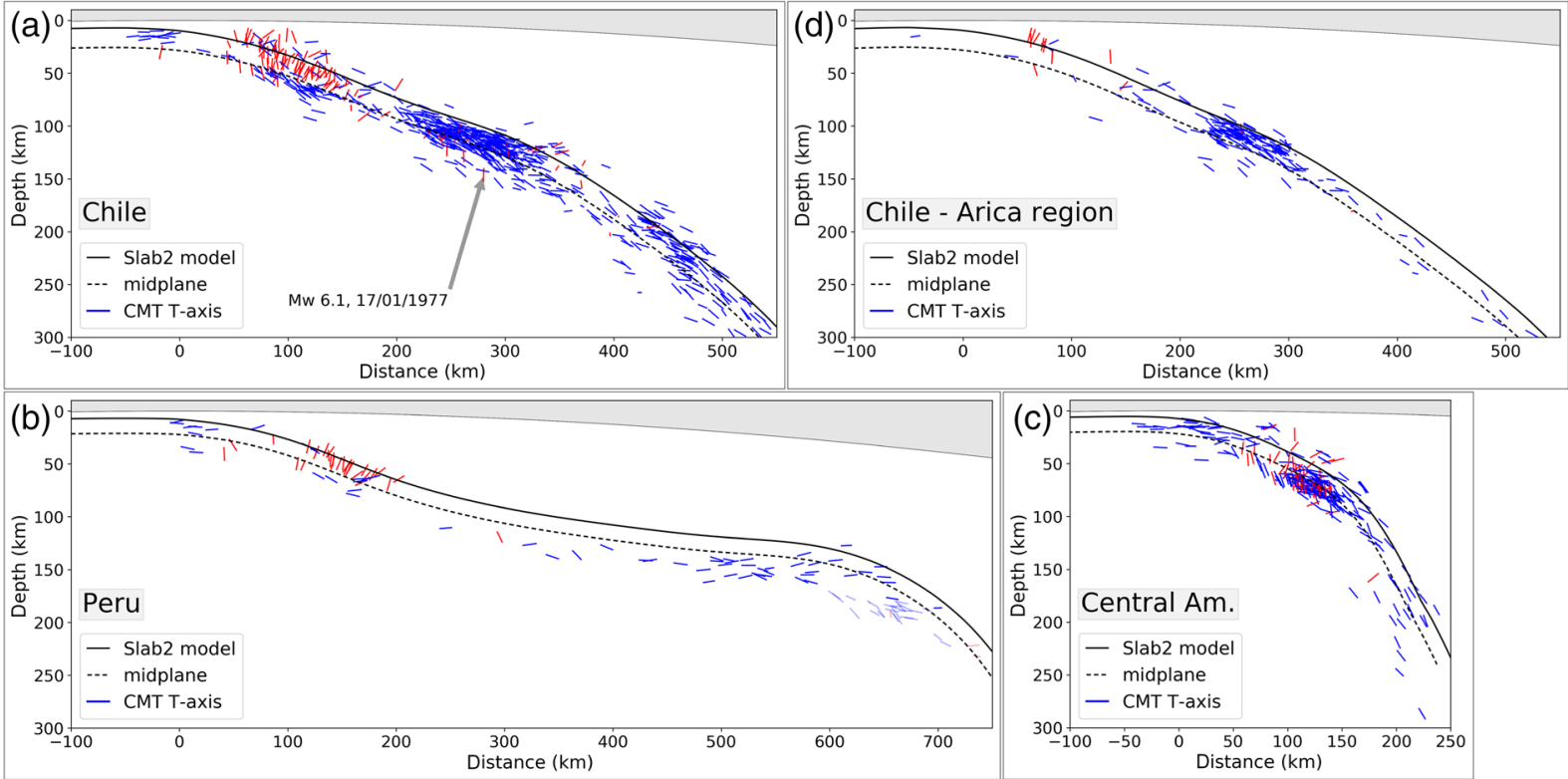

Figure 5. ePac slab profile sections: (a) Chile; (b) Peru; (c) north Chile (Arica region); (d) Central America. See Figure 3 caption for details of figure organization and preparation.

Kuriles slab (Figure 3b) where a clear offset in the locus of DC and DT events occurs at depths between 70 and $200 \mathrm{~km}$. The polarity switch is also evident in both Tonga and Japan, although in both cases, the relative proportion of lower plane DT to upper plane DC events is lower than in the Kuriles (e.g., Kawakatsu, 1986b). Importantly, while the PUZ in both Tonga and Japan is dominated by DC events, neither are exclusively DC, and in both regions DT events are systematically further from the slab surface (Figures $3 a$ and $3 b$ ). As we discuss below this is contrary to the expectation of uniform slab shortening proposed in previous studies (e.g., Fujita \& Kanamori, 1981; Isacks \& Molnar, 1971; Richter, 1979).

In Japan, a polarized DSZ is clearly evident in the PUZ at depths between 60 and $200 \mathrm{~km}$. Compared with the Kuriles, lower plane DT events are more clustered and occur further downdip than the upper plane DC events. The great Tohoku megathrust event in 2011 occurred during the catalog interval considered here, resulting in a large cluster of extensional earthquakes in the shallow part of forearc (labeled in Figure 3c Imanishi et al., 2012). The Tohoku Earthquake also had a significant effect on the intraslab seismicity rate. For example, a comparison of Figures $3 \mathrm{c}$ and $3 \mathrm{~d}$ suggests that OBZ activity rates following the Tohoku Earthquake have been substantially elevated, consistent with a positive static stress change. Interestingly, the number of unbending (PUZ) events did not increase to the same extent. In particular, very few additional lower plate (DT) events occurred since 2011. This suggests that stress changes following the megathrust rupture were less significant in the deeper part of the slab than in the shallower parts. These observations reinforce the notion that even when geometric bending strain accumulation is expected, its seismic expression is quite variable and can be impacted over timescales of at least a decade by associated large megathrust ruptures. Despite the changes in seismicity rates since 2011, the basic aspects of the seismic expression are similar to earlier events.

The along-strike morphology of ePac slabs tends to be more variable than wPac slabs and includes prominent flat slab segments in Chile (Pampean), Peru, and Mexico. An important consequence is that ePac slabs commonly exhibit additional zones of bending and unbending downdip from the PUZ. An issue in characterizing ePac seismicity relates to the relatively low rates of OBZ and PUZ seismicity. Resolving their seismic expression requires aggregating earthquakes over significant distances along-strike $(\sim 1,000 \mathrm{~km})$. Because the slab morphology is relatively coherent at shallow depths, the analysis of aggregated earthquakes in the OBZ and PUZ is typically quite straightforward. However, with increasing downdip distance, this coherence degrades, and the deeper seismic expression of ePac slabs tends to be less well resolved compared to wPac slabs. These issues are most significant in Chile in the vicinity of the Pampean flat slab where the 
Juan Fernandez Ridge subducts beneath the Andes (Figure 4a). However, here we treat the entire region as a single extended domain because: (a) the Pampean flat slab is relatively narrow and has low intermediate depth seismicity rates compared to the northern part of the Chile slab (i.e., the north Chile seismic belt, shown in Figure 4a) and (b) OBZ and PUZ seismicity rates are generally low but much more uniformly distributed, and so the extended domain provides a well-resolved view of OBZ and PUZ seismicity.

Compared with wPac settings, ePac OBZ seismicity tends to be clustered much closer to the trench and with fewer recorded events. In Peru, OBZ events are located within about $10 \mathrm{~km}$, with a locus of activity slightly landward, of the trench (Figure 5a). In the PUZ, clusters of earthquakes occur about $100 \mathrm{~km}$ inboard of the trench in Chile and $150 \mathrm{~km}$ in Peru (Figures 5a and 5b). In both cases, a band of dominantly DC events overlies a smaller band of DT events. As discussed in section 5, these events occur in regions where inferred rates of PUZ unbending are highest. The relatively shallow depth of ePac PUZ seismicity means it partly underlies the megathrust zone, and so filtering megathrust events is critical to their resolution. While the significance of ePac DC events in terms of a putative unbending DSZ was noted as long ago as 1976 (e.g., Barazangi \& Isacks, 1976), it has largely been overlooked, and other studies have argued for alternative explanations such as slab push (Lemoine et al., 2002) and flexural slip (Romeo \& Álvarez-Gómez, 2018).

Downdip from the PUZ, the morphology of the Chile and Peru slabs deviates substantially. Peru has a very long $(\sim 300 \mathrm{~km})$ flat slab region, followed by a second zone of steepening along the distal hinge of the flat slab section. The peak in curvature occurs at around $600 \mathrm{~km}$ from the trench. The "regional-average" slab morphology for Chile (Figure 5a) does not contain a prominent flat slab sensu stricto. However, a subtle upward deflection beginning at around $200 \mathrm{~km}$ from the trench is indicative of partial flattening. Despite its subtle form, the implied curvature gradient is significant, consistent with high rates of geometric bending.

In both Chile and Peru, slab seismicity at classic "intermediate depths" is dominated by DT events. In Peru, DT seismicity is distributed throughout the flat slab, becoming more frequent toward the distal hinge, with an average depth of $\sim 120 \mathrm{~km}$ and a slight concave up distribution when projected on slab normal sections (see Figure S6). A cluster of earthquakes known as the Pucallpa seismic nest (Figure 5c) is located proximal to a localized depression in the slab along the distal hinge of flat slab (Gutscher et al., 2000; Wagner \& Okal, 2019). In Chile, the DT events are clustered in two zones. The first overlaps with the zone of partial slab flattening, between 200 and $350 \mathrm{~km}$ from the trench, centered at a depth of $\sim 110 \mathrm{~km}$ (as depicted by red points in Figure 4a). The second cluster is more diffuse, concentrated between 400 and $500 \mathrm{~km}$ from the trench and depths of $150-300 \mathrm{~km}$ (displaying as blue points in Figure 4a). As most evident in trench-parallel section (see Figure S6), the shallower zone forms a subhorizontal band best developed in the north (labeled "north Chile seismic belt") but clearly present in parts of the slab further south. The deeper second zone forms a steeply oriented band shallowing to the south (highlighted with a red dashed line in Figure S6). The clustering of these deeper earthquakes is indicative of deformation with strong lateral variability. Our study, which focuses on flexural deformation in the 2D trench perpendicular plane, is unable to determine any meaningful geometric correlations when such clear along-strike (or 3D) variations are present.

The projections of seismicity onto the "regional average" slab model highlights the limitations of existing slab models for Peru. For all other slabs, the locus of intermediate depth seismicity occurs in the upper 20-30 kms of slab, at or above the slab midplane, consistent with the expectation that seismicity is concentrated in the cooler parts of the slab (Emmerson \& McKenzie, 2007). For Peru, intermediate depth seismicity projects at a significantly deeper level relative to the slab models, mostly below the midplane. We suspect this reflects systemic errors in the slab models for Peru, as for example identified by Rosenbaum et al. (2019), with the Slab2 model around 20-30 km too shallow.

The Central American Slab is the most seismically incoherent of the slabs sections described here, presumably because morphological variability blurs the patterns of aggregated seismicity, even at shallow depths (Figure 5c). Hypocenter locations exhibit substantial scatter at all depths and less pronounced downdip clustering than is evident in Chile or Peru. Based on the region-averaged geometry, the Central America slab is characterized by two distinct zones of steepening (Figure 5c). After bending through the OBZ, the slab unbends fully at about 100-km distance from the trench, before steepening again with a second peak in curvature at about $175 \mathrm{~km}$. Unlike the other ePac slabs, there is no distinct reduction in dip angle between the peaks in positive curvature (we note that a little further north beneath Mexico, there is a prominent flat slab, 
which shows many similarities to the Peruvian flat slab in terms of relationships between seismicity and geometry as discussed in detail by Sandiford, Moresi, Sandiford, \& Yang, 2019). The majority of earthquakes in this segment of the Central American Slab have DT mechanisms and are concentrated at a distance of about $130 \mathrm{~km}$ from the trench in a zone of curvature increase where, similar to the outer rise, flexural stretching of the upper part of the slab is expected. While several DC events (red axes in Figure 5c) could potentially indicate unbending in the PUZ, there is no clear spatial separation between DC events and the more numerous DT earthquakes. Moreover, Figure 5c shows that the principal axes of the DC events are not preferentially aligned with the slab dip direction, as is expected for flexural unbending, and may reflect a more prominent role for out of plane bending or that the variations in slab morphology are significant and poorly represented by the region-average geometry.

\section{Insights From Numerical Modeling}

In this section, we describe results of a numerical subduction model, which provides insight into the relative contribution of different modes of slab deformation, as well as the geometric controls on flexural deformation. The setup is comparable to recent studies, where flow is driven entirely by the thermal density contrast of the plate slab, which develops as a naturally evolving thermal boundary layer at the surface (Agrusta et al., 2017; Garel et al., 2014). The model setup is described in detail in the supporting information S1 (see also Sandiford \& Moresi, 2019). Mantle rheology (including oceanic lithosphere) is prescribed by a composite flow law including linear high-temperature creep and a scalar viscoplasticity designed to capture both psuedo-brittle as well as distributed plastic deformation within the slab. We assume the stored elastic stress component is relaxed over relatively short time/length scales and can be neglected.

An important feature of the model is the evolution of partial slab flattening. This morphological evolution is concomitant with a overall reduction in subduction velocity between 10 and 25 million years and a shift to intense shortening of the upper plate. Indeed, this shared set of features has been discussed in a number of recent modeling studies, in terms of interplay between the sinking/retreating slab and the structure of the compensating return flow (Faccenna et al., 2017; Yang et al., 2019). In particular, the dynamics exhibited in $2 \mathrm{D}$ models, where the trench is capable of retreat but toroidal flow is absent, bears a close resemblance to Chilean-type subduction systems, consistent with the idea that the central Andean orocline represents a stagnation point for upper mantle toroidal flow (Russo \& Silver, 1994).

Figure 6 shows the downdip component of the strain rate $\left(\dot{\epsilon}_{s s}\right)$ at two time intervals, with the top panels in each figure showing the normalized value of curvature and curvature gradient evaluated along the slab midplane. The fact that flexural deformation dominates the strain rate field is evident in the strong polarization, with zones of shortening (red) on one side of the slab always accompanied by similarly elevated stretching (blue) on the other side. Despite the flow being driven by the thermal buoyancy contrast of the slab, the fact that the slab strain rates are polarized rather than uniform implies that the slab pull force is substantially compensated by drag in the mantle. This subduction style is often referred to as the Stokes regime (Capitanio et al., 2007; Ribe, 2010; Schellart, 2004). The stress in the subducting plate at 10 myr is shown in the inset in Figure 6. The peak stress of order $10 \mathrm{MPa}$ is an order of magnitude lower would be than anticipated if a significant component of the buoyancy deficit were transmitted to the trailing surface plate (i.e., when the slab pull factor is $~ 0.5$, e.g., Conrad \& Lithgow-Bertelloni, 2004).

The model also highlights the strong geometric control on deformation rates for slabs in the Stokes regime. For a slab that deforms by pure bending, the distribution of strain rate in the downdip direction $\left(\dot{\epsilon}_{s s}\right)$ is a function of the curvature rate multiplied by distance from the midplane (Kawakatsu, 1986a; Ribe, 2001; Tsukahara, 1980):

$$
\dot{\epsilon}_{s s}=-y \frac{D K}{D t}=-y\left(\frac{\partial K}{\partial t}+u_{s} \frac{\partial K}{\partial s}\right)
$$

where $s$ refers to a unit vector along the slab midplane, $y$ is the distance perpendicular to the midplane, $\frac{D}{D t}$ is the material derivative following $s, K$ is the curvature, and $u_{s}$ is the velocity component parallel to the midplane. The term $u_{s} \frac{\partial K}{\partial s}$ is sometimes referred to as the advective or kinematic bending rate, but we use 

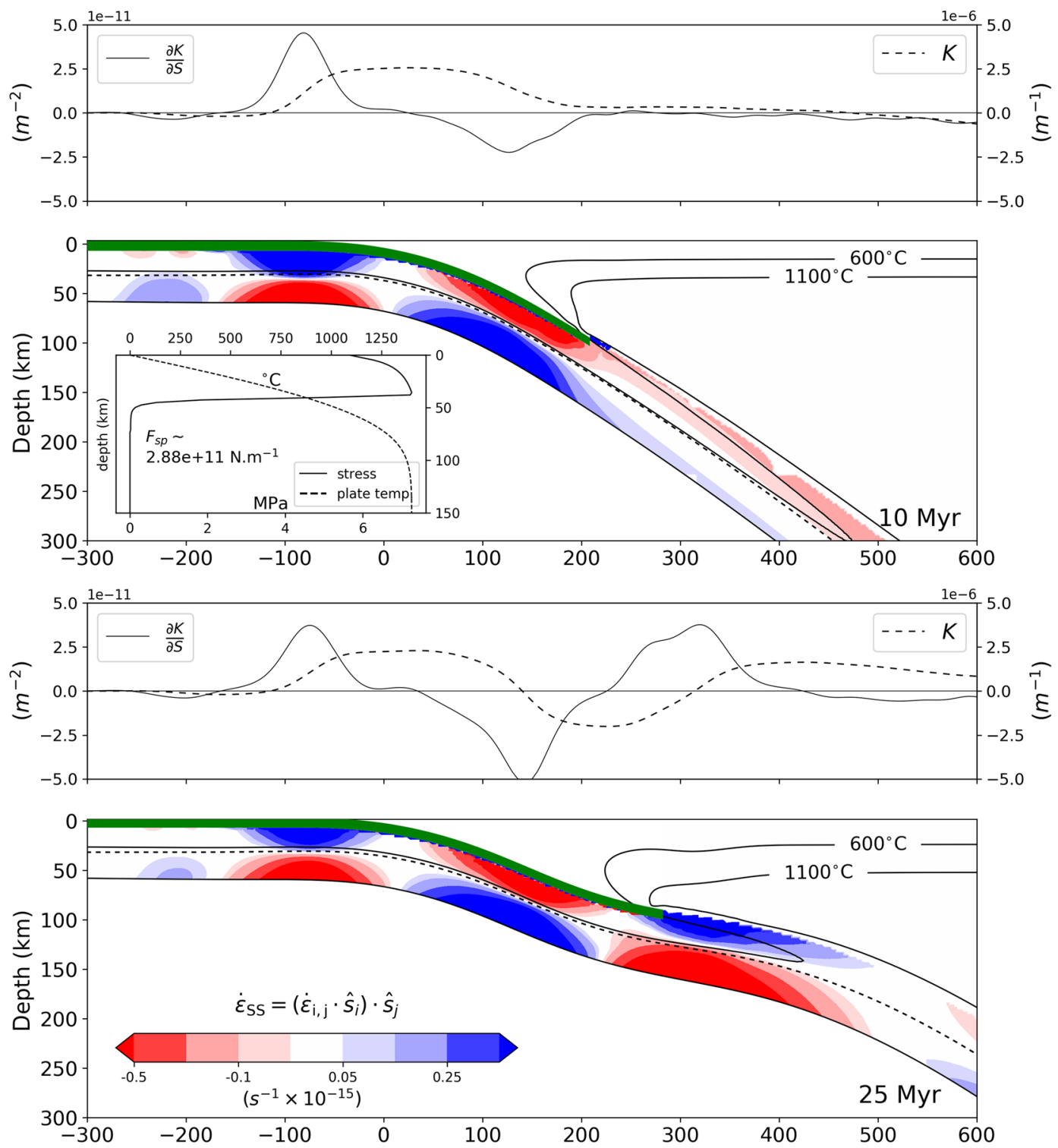

Figure 6. Strain rate distribution in numerical model at 10 and $25 \mathrm{Myr}$. For each figure, the main panel shows the downdip strain rate component in the slab $\left(\dot{\epsilon}_{s s}\right)$ resolved parallel to the slab midplane. We show only the strong interior part of the slab: the subduction interface zone, upper plate, and parts of the mantle above the $1100^{\circ} \mathrm{C}$ isotherm and have been masked. +ve values (blue) show zones of downdip extension; -ve values (red) are shortening. Solid black lines show isotherms as labeled. Dashed black line is the slab midplane. Shaded green region represents the subduction interface. Inset in the panel at time $10 \mathrm{Myr}$ shows the temperature and stress (horizontal component) profile in the plate at $300 \mathrm{~km}$ to the LHS of the trench. The upper panels show the curvature and curvature gradient of slab midplane, plotted along the same horizontal axes as the main panels (distance from trench).

the term geometric bending rate to emphasize the fact that it is the present day slab geometry that constrains the time-independent component of the bending rate.

Figure 6 shows that the curvature gradient $\left(\frac{\partial K}{\partial s}\right)$ correlates strongly with the downdip strain rate in the model $\left(\dot{\epsilon}_{s S}\right)$, with both tending to zero as the local curvature amplitude maximizes as expected when geometry is a dominant control on the both the total bending rate and the overall slab deformation rate. At $10 \mathrm{Myr}$, a rather typical slab morphology is characterized by plate bending outboard of the trench (OBZ) with unbending in the PUZ centered at around 70-km depth. At $25 \mathrm{Myr}$, an upward deflection at intermediate depths produces a secondary positive curvature gradient zone characterized by extension in the upper part of the 
slab above a zone of shortening in the lower half bearing a marked similarity to the partial flattening of the Nazca Slab in northern Chile (Figure 4a).

Because the brittle ductile transition in lithospheric mantle is thought to occur at a potential temperature near $600^{\circ} \mathrm{C}$ (Emmerson \& McKenzie, 2007), the distribution of slab temperature is key to understanding the seismic expression of slab deformation. In our model, the gradual reduction in subduction velocity between 10 and 25 myr means the maximum depth of the $600^{\circ} \mathrm{C}$ isotherm reduces from about $300 \mathrm{~km}$ to less than $150 \mathrm{~km}$ over that time interval. We note that because the modeled $600^{\circ} \mathrm{C}$ isotherm encloses the upper half of each bending region, we expect the seismic strain release would be strongly asymmetric and mainly restricted to part of the slab above neutral plane. For a given slab, the degree of seismic asymmetry will likely be sensitive to its thermal structure, as well as variations in the level of in-plane stress (Craig et al., 2014).

\section{Seismicity-Geometry Relationships}

In this section, we explore the relationship between geometric bending and the seismic expression of each of the Pacific margin slabs discussed in section 3. Within each slab region, the relative variation in the geometric bending rate is associated with downdip curvature gradient of the neutral plane, in accord with Equation 2. We calculate curvature gradient using the estimated slab midplane as a proxy for the neutral plane, as described in the supporting information S1. To visualize these relationships, we project the earthquake $T$-axes in a slab midplane coordinate system, with distance from the hypocenter to the midplane shown on the vertical axis and distance along the midplane relative to the trench on the horizontal. As in the earlier figures, the $T$-axes are projections on to a trench normal plane; in this case, they are additionally rotated so that the angle relative to the midplane is preserved.

Figure 7 shows seismicity geometry relationships for the wPac regions. The curvature gradient profiles associated with wPac slabs show a relatively symmetric positive peak, with a half-wavelength of between 150 and $200 \mathrm{~km}$. Peak curvature (zero gradient) occurs at a considerable distance $(50-100 \mathrm{~km})$ downdip from the trench. Beyond this, the downdip gradient changes sign and thereafter tends to decay monotonically as the slab fully straightens in the mid-upper mantle.

In wPac slabs, OBZ earthquakes tend to cluster either near the peak in positive curvature gradient (e.g., Kuriles) or between the peak in curvature gradient and the peak in curvature (e.g., Japan and Tonga), but not at the peak in curvature. A key feature of all wPac slabs is the shift from dominant DT earthquakes to dominant DC earthquakes in the upper slab accompanying the transition from OBZ to PUZ where the curvature gradient switches sign. This statement neglects the shallow normal earthquakes landward of the Japan Trench, as these are assumed to originate in the forearc (as labeled in Figure 7c). Nevertheless, there are some obvious differences in the seismic expression. For example, in the Kuriles, the OBZ-PUZ transition is marked by a zone of relatively intense seismicity, where $T$-axes orientation is somewhat disorganized, before the characteristic polarized unbending DSZ emerges. In this transitional region, many of the DC Taxes are slightly counter-clockwise rotated from the slab orthogonal/vertical. This may indicate the presence of unidentified megathrust events. In Tonga, the transition in $T$-axis polarity is sharper and coincides remarkably closely with the change in sign of the curvature gradient. In Japan, the transition to negative curvature gradient coincides with the onset of upper plane DC seismicity, whereas lower plane DT events only appear a further 100-km downdip. Whereas Tonga shows a much higher proportion of upper plane DC to lower plane DT events, the Kuriles is characterized by a more symmetrical distribution.

The seismicity-geometry relationships for ePac slabs are shown in Figure 8. As noted in section 3, compared with wPac slabs, there are far fewer OBZ ePac earthquakes. As in wPac slabs, they tend to cluster between the peak in curvature gradient and the peak in curvature, rather than coinciding with peak curvature. In Peru, OBZ earthquakes occur beneath the trench itself.

Importantly, the Peru and Chile projections highlight the key and hitherto largely overlooked point that the OBZ-PUZ transition, at the point where the curvature gradient switches sign, marks a switch from dominant upper plane DT earthquake to DC earthquakes, just like wPac slabs. Moreover, Figures $8 \mathrm{a}$ and 8c show that the ePac PUZ DC events are clustered in zones where unbending rates are highest (i.e., at maxima in the absolute curvature gradient). The key insight is that despite occurring at shallower depths than in the wPac, the distributions of PUZ earthquakes in all but the Central American Slab are consistent with a 

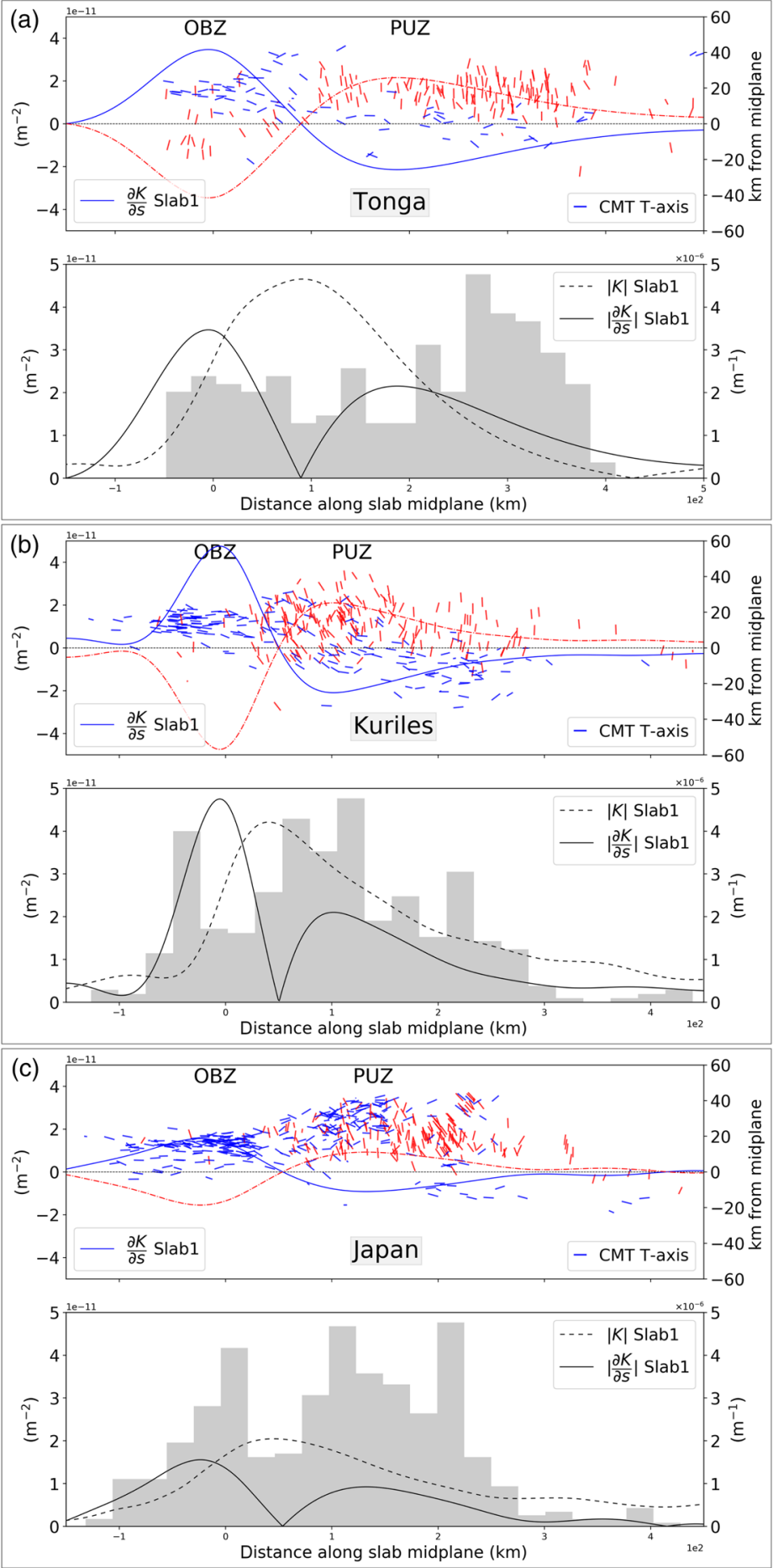

Figure 7. Summary of wPac slab seismicity-geometry relationships. (a) Tonga, (b) Kuriles, and (c) Japan. Top panels show CMT T-axes plotted in a slab midplane coordinate system, with distance from the hypocenter to the midplane on the vertical axis, and distance along the midplane relative to the trench on the horizontal axis. The $T$-axes have been rotated so that the angle relative to the midplane is preserved. The length variation in the plotted $T$-axes reflects the magnitude of the projected component of the vector. The blue solid line shows the value of the curvature gradient plotted against the distance along the midplane. The red dashed line shows the reflection of the curvature gradient about the midplane. Together, these lines show parts of the slab that are expected to be stretching (blue half) and shortening (red half), due to the geometric component of the bending rate. For each regions, the bottom panel includes a histogram showing the relative variation in number of slab earthquakes as a function of distance along the midplane with the solid and dashed lines showing the absolute value of the midplane curvature and the curvature gradient. 

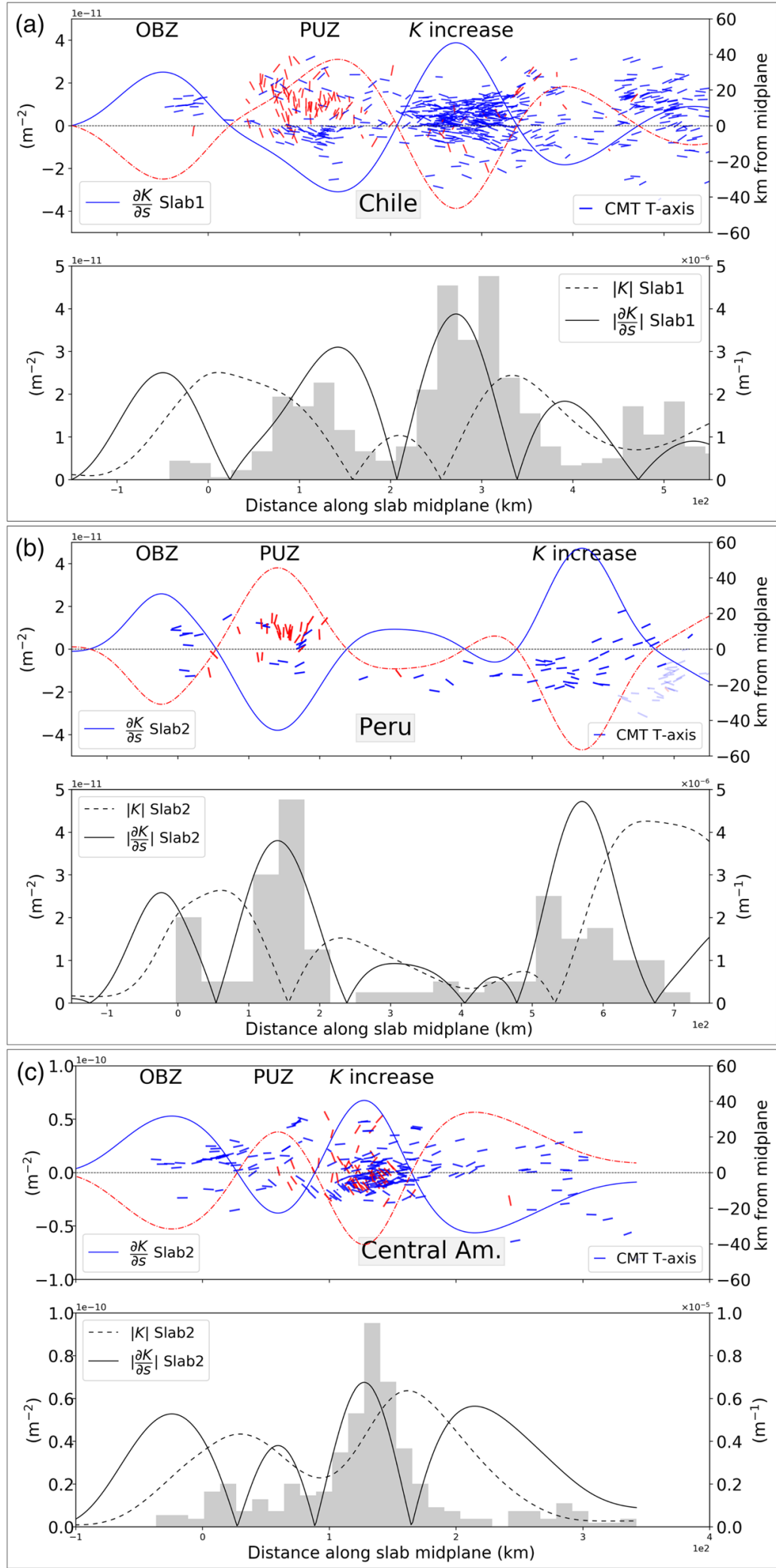

Figure 8. Summary of ePac slab seismicity-geometry relationships. (a) Chile, (b) Peru, and (c) Central America. See caption to Figure 7 for further details. 
common mechanism. The Central America is the exception, with the zone of normal faulting (DT) continuing in the landward direction past the point when the curvature gradient changes sign. These patterns clearly do not fit with the systematic variation with geometric bending observed elsewhere.

Whereas the wPac slabs unbend monotonically, the ePac slabs typically exhibit additional zones of positive (and negative) curvature gradients. In northern Chile, a zone of positive curvature gradient occurs at about 200-km downdip from the trench (Figure 8a), corresponding to the partially flattened slab, which is expected to induce flexural extension in the upper half of the slab. This zone has a strong spatial overlap with the belt of DT seismicity along the Chile slab at approximately 100-km depth, the most active expression being the north Chile seismic belt (see Figures 4a and S6). The full downdip seismic expression is most spectacularly revealed in Chile, where a remarkable set of transitions from upper plane DT (OBZ) to DC (PUZ) and then back to DT quakes is evident where the slab is partially flattened. In each case, the transition correlates with a change in sign of the curvature gradient and minima in seismic activity rates.

There are several caveats in relating the intermediate depth earthquake belt in Chile with flexural deformation. The first is the near absence of deeper DC events in the CMT catalog, as would be expected by the positive bending rate. Ultimately, we argue that this is simply the result of predominately ductile deformation beneath the neutral plane. This interpretation is elaborated in section 6 . Nevertheless, there is fragmentary evidence in the seismic record that shortening underlying the neutral plane can lead to seismic rupture. In a regional study of microseismicity, Comte et al. (1999) resolved DC events which were systematically deeper that the DT events, a pattern they referred to as an "oppositely polarized" DSZ. Araujo and Suárez (1994) discuss a well-located DC event at a depth of $152 \mathrm{~km}$, around $35 \mathrm{~km}$ below the cluster of DT events. They posit that this "inverted" DSZ may be linked to the flexural stresses induced by the change in dip. A second issue is a small number of DT events that project well below the inferred midplane and would seem to be more consistent with uniform downdip stretching of the slab. Given the lateral variability in Chile slab morphology, we suspect that these anomalously deep DT events are mislocated when projected onto our "regionalaverage" projection. To test this, Figure $5 \mathrm{~d}$ shows a section covering a narrower region within the north Chile seismic belt. For this smaller region, in which such projection uncertainties are significantly reduced, a very high proportion of hypocenter locations projects in the upper $\sim 20 \mathrm{~km}$ of the slab, consistent with DT seismicity being localized in a rather narrow region, consistent with the brittle strain regime being mainly restricted to depths above the neutral plane.

While the distribution of seismic activity rates across the Peru flat slab matches the general form of the curvature gradients (Figure $8 \mathrm{~b}$ ), as noted earlier, the projection places the majority of these events beneath the slab midplane of the Slab2 model. There is no record of deeper DC events in this region, and so the significance of this distribution remains uncertain. However, as noted, the locus of Peruvian intermediate depth seismicity is much further below the projected slab surface than for Chile, as well as the other slabs analyzed here. This suggests systematic errors in the Slab2 model for the Peruvian flat slab, with the model surface likely in error by $20-30 \mathrm{~km}$, and likely underestimating the extent of flattening, which may even lead to negative dip angle at $\sim 500 \mathrm{~km}$ from the trench.

In Figure 8b, a group of slightly deeper earthquakes include the Pucallpa seismic nest cluster at the distal edge of the domain at distances $>650 \mathrm{~km}$ from the trench, in a region of negative curvature gradient (Figure 8b). These events are proximal to a relative localized lateral perturbation of the slab morphology, at the landward edge of the flat slab (Gutscher et al., 2000; Wagner \& Okal, 2019). This suggests that the role of out of plane slab deformation may be significant in this region. Out of plane deformation, along with time-dependent modes of deformation (i.e. changes in slab geometry that are occurring in an upper plate reference frame) can be expected to contribute to the slab strain rate field in ways that obscure the simple $2 \mathrm{~d}$ geometric correlations explored here.

\section{Discussion}

In view of the many sources of uncertainty, attempting to elucidate the contribution of geometric bending from the seismic expression of deforming slabs represents a significant challenge. As discussed earlier, the sources of uncertainty include the earthquake hypocenters, slab geometry models, the impact of out of plane bending and other modes of deformation, and finally the confounding effects of temperature and metamorphism in promoting or impeding brittle deformation. Despite these limitations, we have shown that 
in at least five of the six regions described, the seismic expression is remarkably consistent with the expectations of flexural strain accumulation. Whereas the prevailing conceptual models sees contrasting intermediate depth seismic expression as a consequence of fundamental differences in the slab force balance, our framework suggests that they are largely explicable in terms of differences in geometry. This is a significant finding with many ramifications, some of which we discuss more fully below. In so doing, we are not claiming that flexure via geometric bending is the only source of stress responsible for slab seismicity. This is clearly not the case. However, the recognition that geometric bending plays significant provides important constraints on slab dynamics from the perspective of slab strength and stress state, in particular.

\subsection{Seismicity Related to Unbending}

In reference to Japan, Kawakatsu (1986a) argued that peak rates of geometric unbending were likely to be higher than uniform stretching due to slab pull. Yet it is only in a few regions, northern Japan, Kuriles and Aleutians, where unbending has been recognized as a dominant control on slab seismicity. In particular, with the exception of Isacks and Barazangi (1977), the role of unbending has seldom been discussed in the context of ePac slabs (to the best of our knowledge). In this study, we have shown that earthquakes consistent with unbending are present in all the wPac and ePac margin slabs, excepting Central America where DC earthquakes seem absent in the putative PUZ. We note, however, that along other sections of the Middle America Trench, DC earthquakes characteristic of unbending are present such as in the Mexican flat slab region (Sandiford et al., 2019). In most cases, the PUZ is expressed as a polarized DSZ, with DC earthquakes occurring at shallower levels than a dominantly DT band. These polarized DSZs are consistent with the seismic expression of shortening/extension either side of the neutral plane. However, the proportion of DT earthquakes relative to DC in the PUZ is quite variable, as exemplified in the difference between Tonga and Kuriles (Figures 3a and 3b). We discuss this variability in the following sections.

A number of factors make the seismic expression of unbending in ePac slabs less obvious than in wPac slabs. ePac PUZs are shallower than the normal intermediate depth specification $(>70 \mathrm{~km})$ and have often been ignored in studies that follow this somewhat arbitrary designation. Moreover, the close proximity of ePac PUZ events to the megathrust means that filtering the intraslab earthquakes from the interplate is essential. Finally, at the magnitude range of the CMT catalog, resolving the seismic expression of ePac PUZ requires aggregating seismicity over significant distances.

Despite the challenges in resolving the shallow slab seismicity, we are confident that the DSZs we have linked with ePac unbending are robust features. First, we have shown that in Peru and Chile, the DSZs have the correct polarity and are located precisely where the slab models predict peak rates of curvature reduction (e.g., Figure 8). Second, we are confident that DSZs do comprise intraslab events, rather than grossly mislocated and atypical megathrust or upper plate ruptures. Indeed, the occurrence of isolated DC earthquakes in the unbending zone in the Nazca Plate has been discussed by a number of previous studies. Lemoine et al. (2002) described these as "slab push earthquakes" to distinguish them from what they regarded as the more typical "slab pull” DT earthquakes. Isacks and Barazangi (1977) suggested that DC earthquakes in Peru are related to unbending, an interpretation that our study supports. Fuenzalida et al. (2013) provide high-resolution aftershock solutions following a medium-size DC event in the unbending zone of the Chile slab (Mw 6.1 Michilla Earthquake, 16 December 2007). The aftershock sequence delineates a near-vertical fault plane between about 40 and $50 \mathrm{~km}$ depth (likely crossing the slab moho). This orientation is consistent with reactivation of a landward-dipping outer rise normal fault plane and provides an important insight into the rupture character of a shallow DC unbending event. The identification of a compelling unbending signal in the Nazca Plate in Chile and Peru extends the applicability of Kawakatsu's argument that peak rates of geometric unbending should exceed the background rate of uniform stretching due to slab pull.

\subsection{Geometric Bending and Contrasting Seismic Expression}

In the wPac slab regions we have considered, inferred rates of unbending decay monotonically as slabs straighten in the mid-upper mantle, consistent with a gradual falloff in seismicity rates with depth. Whereas wPac slab morphologies represent a "textbook" view of subduction, ePac slabs are generally more complicated with alternating fully and partially flattened slab sections (Engdahl et al., 1998; Hayes et al., 2018; Isacks \& Barazangi, 1977). We argue that these systematic geometric differences are the key control on the contrasting seismic expression of ePac and wPac slabs at intermediate depths. Analysis of the 

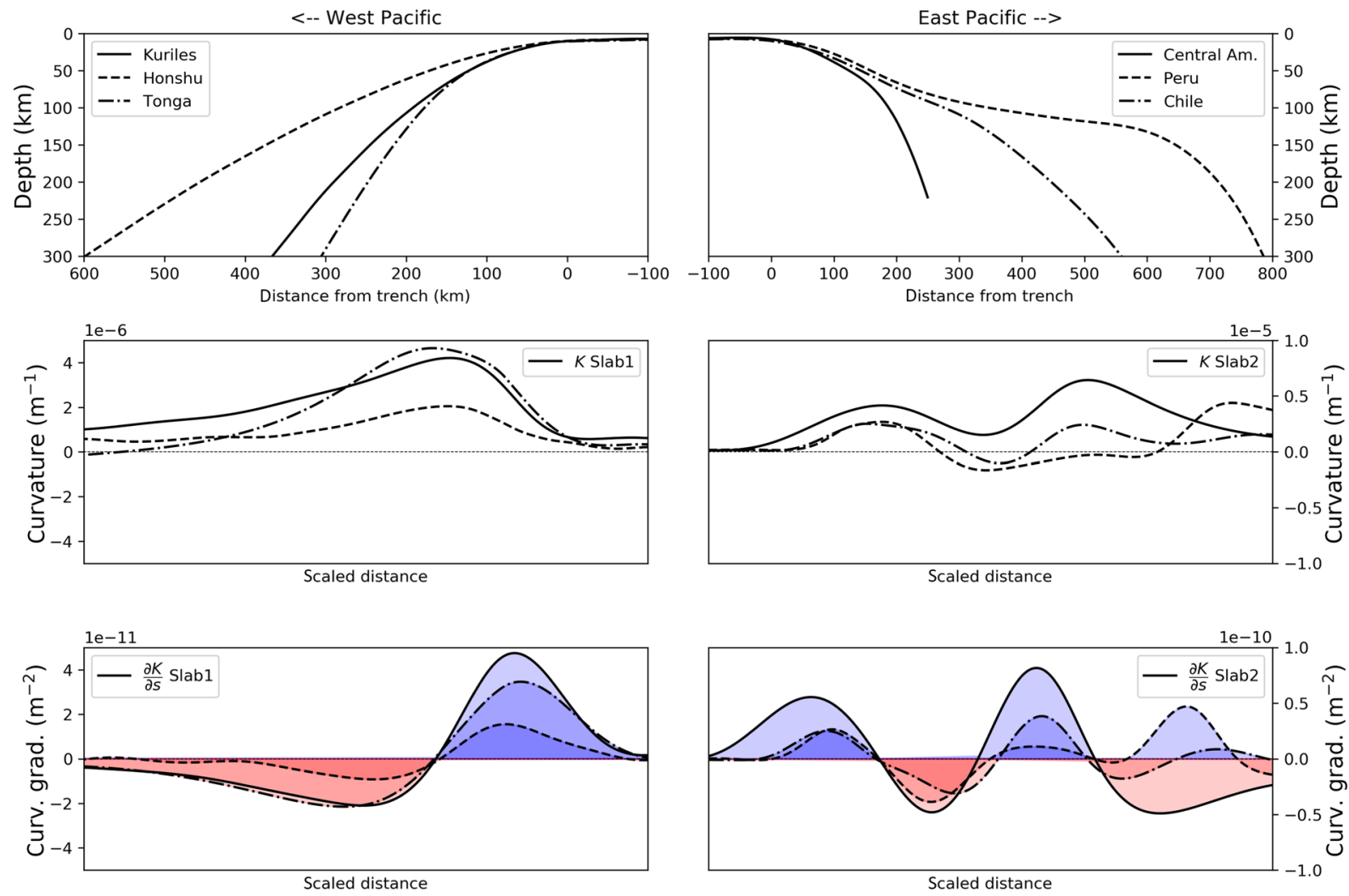

Figure 9. Comparison of characteristic features of wPac (left) and ePac (right) slab geometries. Upper panel shows slab profiles, middle panel shows curvatures, and lower panels show curvature gradients. The geometric rate of bending is governed by the curvature gradient. In the lower two panels (either side), we have scaled the horizontal distance (distance along the midplane) so that the transition from the OBZ to the PUZ lies at the same point (i.e., the first zero crossing of the curvature gradient is equal for the ePac and wPac groups, respectively). The color is indicative of the anticipated sense of deformation above the neutral plane: blue, extension; red, shortening.

downdip curvature gradient shows that the Nazca Plate fully unbends at depths of around $60 \mathrm{~km}$. Beyond this, additional zones of bending are associated with full or partial slab flattening. The majority of ePac DT seismicity is conspicuously clustered in curvature-increasing zones. We summarize these systematic geometric differences between wPac and ePac in Figure 9.

If geometric bending is the dominant control for localizing DT seismicity in ePac slabs, it requires that the lower half of the bending regions (i.e., beneath the neutral plane) is almost completely aseismic. In this light, an important observation is that an oppositely polarized DSZ has been observed in microseismicity, near the northern limit of our Chile study region at $\sim 18^{\circ} \mathrm{S}$ (Comte \& Suarez, 1994). In historical catalogs, only a single moderate sized DC earthquake has occurred at intermediate depths in north Chile (17 January 1977, as labeled in Figure 5). Using depth phases to precisely constrain the hypocenter, Araujo and Suárez (1994) placed this event about $35 \mathrm{~km}$ beneath proximate DT seismicity, consistent with the proposed flexural dynamic state. Indeed, these authors posit that this "inverted" DSZ may be linked to the flexural stresses induced by the change in dip.

These cases notwithstanding, the lack of significant lower plane events in these putative ePac bending zones, like the north Chile seismic belt, may seem at odds with the presence of lower plane events updip in the PUZ. However, this follows a pattern that is quite consistent in most subduction settings we analyze. Specifically, it appears that zones of increasing curvature tend to have less lower plane activity compared to zones of decreasing curvature, or unbending. For instance, whereas OBZs tend to have only limited lower plane DC events, PUZs often have more abundant lower plane DT events. One explanation for this is that the flexural stress state is commonly modified by an in-plane component due to slab pull, acting in a sense of effective tension. This is expected to modify the relative depth of the neutral plane of bending (e.g., Craig et al., 2014; Mueller et al., 1996). In zones of increasing curvature, where the flexural stress state in the 
upper half of the slab is tensional, the addition of in-plane tension shifts the neutral plane deeper, closer to, or even beyond the brittle ductile transition. In zones of decreasing curvature, the opposite applies with the neutral plane shifting toward the slab surface into colder parts of the slab, enhancing the prospect of seismic activity beneath the neutral plane.

In this context, Tonga is somewhat anomalous in showing a more symmetric pattern in the OBZ, with numerous lower plane earthquakes and a more asymmetric pattern in the PUZ with far fewer lower plane earthquakes. This may suggest that, relative to other settings, the magnitude of the uniaxial stress component due to slab pull is significantly reduced or possibly reversed, consistent with earlier ideas that Tonga has a more compressive signal than other slab regions (Gurnis et al., 2000; Isacks \& Molnar, 1971; Nothard et al., 1996). Alternatively, a significant change in slab strength profile may also alter the depth of the neutral plane (e.g., Craig et al., 2014).

\subsection{Slab Rheology, Strain Rates, and Elasticity}

At peak slab curvature, a purely elastic differential stress is predicted in the order of $10 \mathrm{GPa}$. Because this value greatly exceeds inferred yield stresses, inelastic deformation is expected to accommodate the large proportion of bending strains in slabs (Chapple \& Forsyth, 1979), with brittle deformation dominating in the cold regions (Goetze \& Evans, 1979). These predictions are supported by the observation that the cumulative strain of fault throws near the trench (Sleep, 2012), and the seismic moment of OBZ earthquakes (Chapple \& Forsyth, 1979) are close to the total strain (rate) inferred from the change in curvature. An important consequence of inelastic deformation is the fact that the flexural stress state is often inverted with respect to the sign of the slab curvature (Engdahl \& Scholz, 1977). Indeed, the premise that earthquakes occur as a response to slab unbending (where the curvature generally still remains positive) reflects the assumption of significant inelastic deformation. When the slab yield strength is low relative to the potential elastic stresses associated with curvature, the majority of strain is accommodated by inelastic deformation, and the flexural stress state correlates with the bending rate rather than the curvature. When the sign of the bending rate changes, the flexural stress profile inverts and rapidly saturates with the same polarity as the bending rate. In this study, we have emphasized that, to first order, the orientation of seismic moment tensors correlates with the inferred bending rate rather than total strain (i.e. curvature gradient rather than curvature). Overall, our framework supports the conclusion of numerous previous studies suggesting that comprehensive yielding of slabs must occur throughout the subduction hinge (Billen, 2005; Engdahl \& Scholz, 1977; Chapple \& Forsyth, 1979; Goetze \& Evans, 1979).

\subsection{Implications for Subduction Dynamics}

The sources of buoyancy that drive plate motions are often separated into density anomalies in the surface plates (e.g., ridges and other topography) and sublithospheric sources (e.g., slabs, Coblentz et al., 1994; Ghosh et al., 2009). In both cases, the scale of the total anomalous density contribution is relatively well known (Afonso et al., 2007; Turcotte \& Oxburgh, 1967), in comparison to uncertainties in the rheology of plates and mantle. It is the latter that injects substantial complexity and ambiguity in terms in resolving how much of the slab density deficit is propagated through slabs to the surface plates. Attempts to understand the global distribution of plate velocities have concluded that a large fraction of slab weight must be propagated through the slab (Conrad \& Lithgow-Bertelloni, 2002; Forsyth \& Uyeda, 1975; van Summeren et al., 2012). While the presence of intermediate depth DT zones does not constrain the magnitude of stress in slabs, the suggestion that slabs stretch uniformly is clearly compatible with the idea that stresses due to slab pull are significant (e.g., Molnar \& Bendick, 2019). With simple assumptions made about effective slab rheology, stresses in the order of 100s of MPa have previously been estimated (Conrad \& LithgowBertelloni, 2004). While the notion that slabs undergo uniform stretching seems consistent with inferences about the forces driving plate motion, the paradox remains as to why the seismic expression of "slab pull" is evidently not expressed in wPac slabs, which are attached to the fastest moving large plate.

Other lines of evidence suggest slab pull must be significantly smaller than inferred from plate velocity considerations. Coblentz et al. (1994) argued that the intraplate stress field is largely explicable in terms of a balance between lithospheric potential energy distribution and plate-boundary resistance, implying a relatively low degree of slab-plate coupling in plates is the norm. These results are implicit in other modeling studies, which capture the first order features of the intraplate stress field without considering any sublithospheric 
sources (e.g., Ghosh et al., 2009). Away from trenches, earthquakes in ocean basins mainly show thrust faulting (Sykes \& Sbar, 1973), inconsistent with large tensional stress oriented toward subducting slabs. Based on stress indicators in the central Indian Ocean, Sandiford et al. (2005) showed that the effective slab pull fraction must be low, around 0.1 in order to account for large magnitude reverse fault mechanisms observed in the central Indian Ocean with $P$-axes parallel to the Sumatran Trench, implying an average deviatoric tensional stress no more than order $10 \mathrm{MPa}$ propagated via the slab.

The dominant control of bending over stretching in slab seismic strain release is a characteristic of slabs in the Stokes regime, where resistance to slab weight is primarily supplied by drag from the mantle (Capitanio et al., 2009; Goes et al., 2011; Ribe, 2010). In this study, we highlight the fact that slabs in the Stokes regimecan develop highly diverse internal deformation patterns. Indeed, relatively large magnitudes of the curvature gradient, and therefore strain rates, can accompany relatively subtle changes in the slab morphology, as in northern Chile.

A feature of our framework is that it obviates appeals to profound differences in the force balance (or strength) between different slabs, such as is required in the conventional interpretation of uniform stretching in Chile, versus shortening in Tonga (e.g., Chen et al., 2004; Fujita \& Kanamori, 1981; Isacks \& Molnar, 1971). In the geometric bending framework, the contrasts in ePac and wPac seismic expression exemplified by Chile and Tonga arise as a natural consequence of different slab morphology. In the ePac, zones of positive bending rate are associated with full or partial slab flattening. Of course, differences in slab morphology will ultimately be an outcome of the subduction force balance. As our numerical models show, however, slabs may evolve very different morphologies while remaining in the Stokes regime. An important implication of our numerical model is that the evolution of force balance required to produce significant changes in slab morphology (over millions of year periods), may be much smaller than that which would be necessary to produce a transition from flexurally dominated to uniform mode slab deformation.

Recent work suggests that the characteristic ePac/wPac morphology contrasts may be controlled by the interplay between the sinking/retreating slab and structure of the compensating return flow which tends to determine the upper plate kinematics (Faccenna et al., 2017; Yang et al., 2019). In the ePac margins, slab rollback drives a large-scale poloidal return flow, in turn promoting fast trench-ward motion of South America and compression-dominated tectonics in the overriding plate. These conditions have been argued to favor flat slab development along the ePac margin (Manea \& Gurnis, 2007; Schellart, 2017; van Hunen et al., 2004; Yang et al., 2019). In contrast, large-scale downwelling beneath Asia, revealed by seismic imaging, geodynamic models, and plate reconstructions, restrains trench-ward motion of East Asia. Along with the greater ages of wPac slabs, this promotes steeper subduction, extension-dominated upper plate tectonics, and less flat slab subduction episodes along the wPac margin (Yang et al., 2019).

It is important to note that the numerical model presented here is likely to represent an end member example of subduction in the Stokes regime. The reason is that in the 2D setup, the only significant forces that balance slab buoyancy are mantle drag, plate bending, and friction on the subduction interface. When the mantle drag component is largest, the slabs are said to be in the Stokes regime (Ribe, 2010), which is demonstrably the case for our model. In 3D mantle convection, slabs and plates interact with other parts of the flow on a range of scales (Hager \& O'Connell, 1979). This means that individual plates and slabs are influenced by additional tractions, either basally or along plate boundaries, that may either amplify or resist the slab-driven flow. When these additional forces resist motion toward the subduction zone, the compensation of the slab buoyancy within the mantle is reduced, and larger stresses will be propagated through the subduction hinge to the plate. In a 2D modeling setup, these influences may be reproduced, to a degree, when the plate velocity is fixed by surface boundary conditions (e.g., Sleep, 1979). In this case, when the mantle viscosity is reduced, the slab is unable to respond with a proportionate increase its sinking rate. The mantle drag is reduced, a greater component of the slab buoyancy is propagated through the slab to the plate, and the component of uniform stretching, relative to geometric bending, is thus increased (Sleep, 1979). An end member in this type of setup occurs when the velocity of the surface plates is zero, and the attached slab will predominately undergo necking in the asthenosphere.

Following the thread of the preceding paragraph, our framework provides an interesting perspective on the dynamics of intracontinental intermediate depth seismic zones. High seismic strain rates $\left(10^{-14} \mathrm{~s}^{-1}\right)$ have been inferred in the Hindu Kush and the Vrancea Zone beneath the Carpathians (Lorinczi \& 
Houseman, 2009; Molnar \& Bendick, 2019). These are an order of magnitude greater than typical intermediate depth seismic strain in subducting slabs $\left(\sim 10^{-15} \mathrm{~s}^{-1}\right)$. The strain rates beneath the Hindu Kush and Vrancea may indicate deformation dominated by lithospheric necking (e.g., uniform stretching; Lister et al., 2008; Lorinczi \& Houseman, 2009). Meanwhile, as we have argued, earthquakes in Pacific margin subduction zones reflect rates imposed by geometric bending consistent with the observed seismic release rates closer to $10^{-15} \mathrm{~s}^{-1}$ (Kawakatsu, 1986a; Nothard et al., 1996).

\subsection{Limitations and Future Work}

In investigating the potential signal of flexure in slab seismicity, we have focused on the geometric (or advective) component of the bending rate (Buffett, 2006; Ribe, 2001; 2010). The time independence allows us to infer the relative variation in long-term bending rates from present day slab geometry. The geometric component should be the dominant bending term for slabs in which (a) the hinge morphology is not changing rapidly and (b) out of plane contributions to the stress/deformation are relatively minor (Buffett \& Becker, 2012). Clearly, these conditions will not be met in all slab regions, and this caveat will require careful attention in trying to test this hypothesis in other settings. In this study, we have primarily focused on the variation in the orientation of moment tensors with respect to slab geometry in general, especially the curvature gradient. We have been more circumspect about the correlation between seismicity rates and the relative magnitude of the curvature gradient. This is primarily because seismic activity rates are not necessarily proportional to the long term strain rate (i.e., the bending rates inferred via the curvature gradient). The influence of metamorphic processes, and distribution of fluids, in subducting slabs is likely to influence the rates of seismicity. For example, Boneh et al. (2019) have shown that the intermediate depth seismic activity rate varies with the inferred amount of plate hydration in the outer rise region, with similar mechanisms being linked to rapid changes seismic expression along-strike (Shillington et al., 2015). Such process may explain the very different seismic activity rates in the north Chile seismic belt, compared with the Nazca Slab further south (e.g., Figure 4a). Another factor is the increasing role of ductile deformation as the slab heats up from above and below. As a result, the relative amount of seismic/ductile deformation is likely to vary in a complex manner with changes in pressure and temperature. Finally, short catalog times also bias the relative number of earthquakes in different parts of the slab. We highlight, for instance, the increase in OBZ seismicity in Northern Japan following the Tohoku Earthquake.

As noted in section 5, there are a number of instances where the correlation between curvature gradient and seismic expression is ambiguous, absent, or opposite to expectations for a primary geometric bending control. We briefly discuss these below, some of which are readily explained and some not. In the ePac settings, several clusters of seismicity are likely to be unrelated to downdip geometric bending. The Pucallpa seismic nest in Chile appears to be spatially correlated with a relatively localized lateral perturbation of the slab morphology (Gutscher et al., 2000; Wagner \& Okal, 2019), and it is reasonable to assume that these features are related. While for Chile, we demonstrate a close spatial association between the main peak in positive curvature gradient (see Figure $8 \mathrm{a}$ ) and the primary cluster of DT seismicity (the north Chile seismic belt; see Figure 4a), the relationship is less evident at greater depths. Based on our geometric analysis, the slab would be expected to go through an additional zone of unbending (i.e., a secondary unbending zone), where the sign of the curvature gradient returns to negative (e.g., Figure 8a) in analogous fashion to our numerical model, which predicts a return to downdip shortening at around $550 \mathrm{~km}$ from the trench (right side of lower panel in Figure 6). Instead, the intermediate depth seismicity beneath $150 \mathrm{~km}$ remains dominated by DT axes. As we have noted, this deeper cluster is unusual in that it forms a nearly continuous, steeply dipping band that shallows toward the south (as shown in Figure S6).

The apparent absence of deep DC earthquakes associated with upper plane unbending at the expected depth-distance range in ePac slabs, may signal the slab stress deformation state transitions from flexurally dominated to a more prominent uniaxial component (Bloch et al., 2018). Alternatively, progressive warming of the upper part of the slab and/or processes related to dehydration may leave it essentially aseismic at these depths, with the consequence that the seismically active zone lies beneath the midplane. These points high-

light an important caveat in our ability to relate earthquake hypocenters accurately within a geometric framework, as seismicity still provides the best constraint on the geometry. Uncertainties in both hypocentral locations and slab models are significant and require ongoing work. 


\section{Conclusions}

Our study suggests that flexural deformation plays a significant role in the seismic expression of subducting slabs. We have analyzed the contribution of the geometric bending rate and found that in several key locations, the orientation of slab seismic moment tensors vary systematically with the anticipated sense of deformation. The fact that flexure controls seismicity patterns in the OBZ is of course already widely accepted, as is the effect of unbending in a limited number of slab settings. In terms of extending the role of bending/unbending, our contributions are twofold. First, we show that seismicity characteristic of unbending is prevalent in ePac slabs, albeit at shallower depths than wPac slabs. We then show that geometric differences between ePac and wPac slabs lead to additional zones of bending at intermediate depths in ePac slabs. The majority of ePac DT seismicity is conspicuously clustered in these curvature-increasing zones, which are associated with full or partial slab flattening. Hence, the contrasting seismic expression of ePac and wPac slabs appears to arise due to systematic differences in slab morphology rather than differences in in-plane stress associated with either uniform downdip extension in the former or shortening in the latter. The observed correlation of earthquake $T$-axes orientations with the curvature gradient, rather than the curvature, arises from the fact that a very significant proportion of flexural strain is accommodated by inelastic deformation, of which seismic slip itself is a key component. The seismic expression of flexure is strongly modified by the relative contribution of brittle deformation above and below the neutral plane. Within the time frame of historical catalogs, this may range from abundant seismicity in both planes (i.e., the Kuriles PUZ) to virtually no seismicity in the lower plane (i.e., the north Chile seismic belt). A simple qualitative explanation is that the depth of the neutral plane exhibits variability with respect to the thermal structure of slabs, with the latter defining the transition from dominantly brittle to dominantly ductile deformation.

\section{Data Availability Statement}

All data related to seismicity and slab geometry are publicly available: Global CMT data from IRIS: https:// ds.iris.edu/ds/products/, https://ds.iris.edu/spud/momenttensor. The ISC-EHB catalogue from ISC: https:// www.isc.ac.uk/isc-ehb/. The Slab1 model from USGS: https://earthquake.usgs.gov/data/slab/.Tthe Slab2 model from ScienceBase: https://www.sciencebase.gov/catalog/item/5aa1b00ee4b0b1c392e86467. The open source finite element software Underworld2 is available via DOI 10.5281/zenodo. 3738783.

\section{Acknowledgments}

This work was supported by the Australian Research Council (Discovery grant DP150102887). Development of the Underworld2 code (http://www.underworldcode.org/) was supported by AuScope. DS's postgraduate research at the University of Melbourne was supported by a Baragwanath Geology Research Scholarship. This work was supported by resources provided by The Pawsey Supercomputing Centre with funding from the Australian Government and the Government of Western Australia. This work was supported by the Nectar Research Cloud, a collaborative Australian research platform supported by the National Collaborative Research Infrastructure Strategy (NCRIS). The study benefited from discussions and reviews by Greg Houseman, Claire Currie, Norman Sleep, and Laurent Jolivet.

\section{References}

Afonso, J. C., Ranalli, G., \& Fernandez, M. (2007). Density structure and buoyancy of the oceanic lithosphere revisited. Geophysical Research Letters, 34, L10302. https://doi.org/10.1029/2007GL029515

Agrusta, R., Goes, S., \& van Hunen, J. (2017). Subducting-slab transition-zone interaction: Stagnation, penetration and mode switches. Earth and Planetary Science Letters, 464, 10-23.

Araujo, M., \& Suárez, G. (1994). Geometry and state of stress of the subducted nazca plate beneath central chile and argentina: Evidence from teleseismic data. Geophysical Journal International, 116(2), 283-303.

Bailey, I. W., Becker, T. W., \& Ben-Zion, Y. (2009). Patterns of co-seismic strain computed from southern California focal mechanisms. Geophysical Journal International, 177(3), 1015-1036.

Barazangi, M., \& Isacks, B. (1976). Spatial distribution of earthquakes and subduction of the Nazca Plate beneath South America. Geology, 4(11), 686.

Billen, M. I. (2005). Constraints on subducting plate strength within the Kermadec Trench. Journal of Geophysical Research, 110 , B05407. https://doi.org/10.1029/2004JB003308

Billen, M. I., Gurnis, M., \& Simons, M. (2003). Multiscale dynamics of the Tonga-Kermadec subduction zone. Geophysical Journal International, 153(2), 359-388.

Bloch, W., Schurr, B., Kummerow, J., Salazar, P., \& Shapiro, S. A. (2018). From slab coupling to slab pull: Stress segmentation in the subducting Nazca Plate. Geophysical Research Letters, 45, 5407-5416. https://doi.org/10.1029/2018GL078793

Boneh, Y., Schottenfels, E., Kwong, K., Zelst, I., Tong, X., Eimer, M., et al. (2019). Intermediate-depth earthquakes controlled by incoming plate hydration along bending-related faults. Geophysical Research Letters, 46, 3688-3697. https://doi.org/10.1029/ 2018GL081585

Brudzinski, M. R., Thurber, C. H., Hacker, B. R., \& Engdahl, E. R. (2007). Global prevalence of double benioff zones. Science, 316(5830), $1472-1474$.

Buffett, B. A. (2006). Plate force due to bending at subduction zones. Journal of Geophysical Research, 111, B09405. https://doi.org/10.1029/ 2006JB004295

Buffett, B. A., \& Becker, T. W. (2012). Bending stress and dissipation in subducted lithosphere. Journal of Geophysical Research, 117, B05413. https://doi.org/10.1029/2012JB009205

Caldwell, J. G., Haxby, W. F., Karig, D. E., \& Turcotte, D. L. (1976). On the applicability of a universal elastic trench profile. Earth and Planetary Science Letters, 31(2), 239-246.

Capitanio, F., Morra, G., \& Goes, S. (2007). Dynamic models of downgoing plate-buoyancy driven subduction: Subduction motions and energy dissipation. Earth and Planetary Science Letters, 262(1-2), 284-297. 
Capitanio, F., Morra, G., \& Goes, S. (2009). Dynamics of plate bending at the trench and slab-plate coupling. Geochemistry, Geophysics, Geosystems, 10, Q04002. https://doi.org/10.1029/2008GC002348

Chapple, W. M., \& Forsyth, D. W. (1979). Earthquakes and bending of plates at trenches. Journal of Geophysical Research, 84(B12), 6729-6749.

Chen, P.-F., Bina, C. R., \& Okal, E. A. (2004). A global survey of stress orientations in subducting slabs as revealed by intermediate-depth earthquakes. Geophysical Journal International, 159(2), 721-733.

Chen, M., Manea, V. C., Niu, F., Wei, S. S., \& Kiser, E. (2019). Genesis of intermediate-depth and deep intraslab earthquakes beneath Japan constrained by seismic tomography, seismicity, and thermal modeling. Geophysical Research Letters, 46, 2025-2036. https://doi.org/ 10.1029/2018GL080025

Coblentz, D. D., Richardson, R. M., \& Sandiford, M. (1994). On the gravitational potential of the Earth's lithosphere. Tectonics, 13(4), 929-945.

Comte, D., Dorbath, L., Pardo, M., Monfret, T., Haessler, H., Rivera, L., et al. (1999). A double-layered seismic zone in Arica, northern Chile. Geophysical Research Letters, 26(13), 1965-1968.

Comte, D., \& Suarez, G. (1994). An inverted double seismic zone in Chile: Evidence of phase transformation in the subducted slab. Science, 263(5144), 212-215.

Conrad, C. P., \& Lithgow-Bertelloni, C. (2002). How mantle slabs drive plate tectonics. Science, 298(5591), $207-209$.

Conrad, C. P., \& Lithgow-Bertelloni, C. (2004). The temporal evolution of plate driving forces: Importance of "slab suction" versus "slab pull" during the Cenozoic. Journal of Geophysical Research, 109(B10), B10407. https://doi.org/10.1029/2004JB002991

Craig, T. J., Copley, A., \& Jackson, J. (2014). A reassessment of outer-rise seismicity and its implications for the mechanics of oceanic lithosphere. Geophysical Journal International, 197(1), 63-89.

Ekström, G., Nettles, M., \& Dziewoński, A. M. (2012). The global CMT project 2004-2010: Centroid-moment tensors for 13, 017 earthquakes. Physics of the Earth and Planetary Interiors, 200-201, 1-9.

Elsasser, W. M. (1969). Convection and stress propagation in the upper mantle.

Emmerson, B., \& McKenzie, D. (2007). Thermal structure and seismicity of subducting lithosphere. Physics of the Earth and Planetary Interiors, 163(1-4), 191-208.

Engdahl, E. R., \& Scholz, C. H. (1977). A double Benioff Zone beneath the central Aleutians: An unbending of the lithosphere. Geophysical Research Letters, 4(10), 473-476.

Engdahl, E. R., van der Hilst, R., \& Buland, R. (1998). Global teleseismic earthquake relocation with improved travel times and procedures for depth determination. Bulletin of the Seismological Society of America, 88(3), 722-743.

Faccenda, M. (2014). Water in the slab: A trilogy. Tectonophysics, 614, 1-30.

Faccenna, C., Oncken, O., Holt, A. F., \& Becker, T. W. (2017). Initiation of the andean orogeny by lower mantle subduction. Earth and Planetary Science Letters, 463, 189-201.

Forsyth, D., \& Uyeda, S. (1975). On the relative importance of the driving forces of plate motion. Geophysical Journal International, 43(1), 163-200.

Fuenzalida, A., Schurr, B., Lancieri, M., Sobiesiak, M., \& Madariaga, R. (2013). High-resolution relocation and mechanism of aftershocks of the 2007 Tocopilla (Chile) Earthquake. Geophysical Journal International, 194(2), 1216-1228.

Fujita, K., \& Kanamori, H. (1981). Double seismic zones and stresses of intermediate depth earthquakes. Geophysical Journal International, 66(1), 131-156.

Garel, F., Goes, S., Davies, D. R., Davies, J. H., Kramer, S. C., \& Wilson, C. R. (2014). Interaction of subducted slabs with the mantle transition-zone: A regime diagram from 2-D thermo-mechanical models with a mobile trench and an overriding plate. Geochemistry, Geophysics, Geosystems, 15, 1739-1765. https://doi.org/10.1002/2014GC005257

Ghosh, A., Holt, W. E., \& Flesch, L. M. (2009). Contribution of gravitational potential energy differences to the global stress field. Geophysical Journal International, 179(2), 787-812.

Goes, S., Capitanio, F., Morra, G., Seton, M., \& Giardini, D. (2011). Signatures of downgoing plate-buoyancy driven subduction in Cenozoic plate motions. Physics of the Earth and Planetary Interiors, 184(1-2), 1-13.

Goetze, C., \& Evans, B. (1979). Stress and temperature in the bending lithosphere as constrained by experimental rock mechanics. Geophysical Journal International, 59(3), 463-478.

Green, H. W., \& Houston, H. (1995). The mechanics of deep earthquakes. Annual Review of Earth and Planetary Sciences, 23(1), 169-213.

Gurnis, M., Ritsema, J., Heijst, H.-J. V., \& Zhong, S. (2000). Tonga slab deformation: The influence of a lower mantle upwelling on a slab in a young subduction zone. Geophysical Research Letters, 27(16), 2373-2376.

Gutenberg, B., \& Richter, C. F. (1954). Seismicity of the world and associated phenomena. Princeton, NJ: Princeton University Press.

Gutscher, M.-A., Spakman, W., Bijwaard, H., \& Engdahl, E. R. (2000). Geodynamics of flat subduction: Seismicity and tomographic constraints from the Andean margin. Tectonics, 19(5), 814-833.

Hacker, B. R., Peacock, S. M., Abers, G. A., \& Holloway, S. D. (2003). Subduction factory 2. Are intermediate-depth earthquakes in subducting slabs linked to metamorphic dehydration reactions? Journal of Geophysical Research, 108(B1), 2030. https://doi.org/10.1029/ 2001JB001129

Hager, B. H., \& O'Connell, R. J. (1979). Kinematic models of large-scale flow in the Earth's mantle. Journal of Geophysical Research, 84(B3), 1031-1048.

Hasegawa, A., Umino, N., \& Takagi, A. (1978). Double-planed structure of the deep seismic zone in the northeastern Japan arc. Tectonophysics, 47(1-2), 43-58.

Hayes, G. P., Moore, G. L., Portner, D. E., Hearne, M., Flamme, H., Furtney, M., \& Smoczyk, G. M. (2018). Slab2, a comprehensive subduction zone geometry model. Science, 362(6410), 58-61.

Hayes, G. P., Wald, D. J., \& Johnson, R. L. (2012). Slab1.0: A three-dimensional model of global subduction zone geometries. Journal of Geophysical Research, 117, B01302. https://doi.org/10.1029/2011JB008524

House, L. S., \& Jacob, K. H. (1982). Thermal stresses in subducting lithosphere can explain double seismic zones. Nature, 295(5850), 587-589.

Imanishi, K., Ando, R., \& Kuwahara, Y. (2012). Unusual shallow normal-faulting earthquake sequence in compressional northeast Japan activated after the 2011 off the Pacific Coast of Tohoku Earthquake. Geophysical Research Letters, 39, L09306. https://doi.org/10.1029/ 2012GL051491

Isacks, B., \& Barazangi, M. (1977). Geometry of benioff zones: Lateral segmentation and downwards bending of the subducted lithosphere, Island arcs, deep sea trenches and back-arc basins (pp. 99-114). Washington, DC: American Geophysical Union.

Isacks, B., \& Molnar, P. (1969). Mantle Earthquake mechanisms and the sinking of the lithosphere. Nature, 223(5211), $1121-1124$. 
Isacks, B., \& Molnar, P. (1971). Distribution of stresses in the descending lithosphere from a global survey of focal-mechanism solutions of mantle earthquakes. Review of Geophysics, 9(1), 103.

Kawakatsu, H. (1986a). Double seismic zones: Kinematics. Journal of Geophysical Research, 91(B5), 4811.

Kawakatsu, H. (1986b). Downdip tensional earthquakes beneath the Tonga Arc: A double seismic zone? Journal of Geophysical Research, 91(B6), 6432.

Kirby, S., Engdahl, R. E., \& Denlinger, R. (2013). Intermediate-depth intraslab earthquakes and arc volcanism as physical expressions of crustal and uppermost mantle metamorphism in subducting slabs, Subduction top to bottom (pp. 195-214). Washington, DC: American Geophysical Union.

Kita, S., Okada, T., Hasegawa, A., Nakajima, J., \& Matsuzawa, T. (2010). Existence of interplane earthquakes and neutral stress boundary between the upper and lower planes of the double seismic zone beneath Tohoku and Hokkaido, northeastern Japan. Tectonophysics, 496(1-4), 68-82.

Lemoine, A., Madariaga, R., \& Campos, J. (2002). Slab-pull and slab-push earthquakes in the Mexican, Chilean and Peruvian subduction zones. Physics of the Earth and Planetary Interiors, 132(1-3), 157-175.

Lister, G., Kennett, B., Richards, S., \& Forster, M. (2008). Boudinage of a stretching slablet implicated in earthquakes beneath the Hindu Kush. Nature Geoscience, 1(3), 196.

Lorinczi, P., \& Houseman, G. A. (2009). Lithospheric gravitational instability beneath the Southeast Carpathians. Tectonophysics, 474(1-2), 322-336.

Manea, V., \& Gurnis, M. (2007). Subduction zone evolution and low viscosity wedges and channels. Earth and Planetary Science Letters, 264(1-2), 22-45.

McKenzie, D. P. (1969). Speculations on the consequences and causes of plate motions. Geophysical Journal International, 18(1), 1-32.

Molnar, P., \& Bendick, R. (2019). Seismic moments of intermediate-depth earthquakes beneath the Hindu Kush: Active stretching of a blob of sinking thickened mantle lithosphere? Tectonics, 38, 1651-1665. https://doi.org/10.1029/2018TC005336

Mueller, S., Spence, W., \& Choy, G. L. (1996). Inelastic models of lithospheric stress-11. Implications for outer-rise seismicity and dynamics. Geophysical Journal International, 125(1), 54-72.

Nothard, S., McKenzie, D., Haines, J., \& Jackson, J. (1996). Gaussian curvature and the relationship between the shape and the deformation of the Tonga slab. Geophysical Journal International, 127(2), 311-327.

Peacock, S. M. (2001). Are the lower planes of double seismic zones caused by serpentine dehydration in subducting oceanic mantle? Geology, 29(4), 299.

Ribe, N. M. (2001). Bending and stretching of thin viscous sheets. Journal of Fluid Mechanics, 433, 135-160.

Ribe, N. M. (2010). Bending mechanics and mode selection in free subduction: A thin-sheet analysis. Geophysical Journal International, $180(2), 559-576$.

Richter, F. M. (1979). Focal mechanisms and seismic energy release of deep and intermediate earthquakes in the Tonga-Kermadec Region and their bearing on the depth extent of mantle flow. Journal of Geophysical Research, 84(B12), 6783-6795.

Rietbrock, A., \& Waldhauser, F. (2004). A narrowly spaced double-seismic zone in the subducting Nazca plate. Geophysical Research Letters, 31(10), L10608. https://doi.org/10.1029/2004GL019610

Romeo, I., \& Álvarez-Gómez, J. A. (2018). Lithospheric folding by flexural slip in subduction zones as source for reverse fault intraslab earthquakes. Scientific reports, 8(1), 1367.

Rosenbaum, G., Sandiford, M., Caulfield, J., \& Garrison, J. M. (2019). A trapdoor mechanism for slab tearing and melt generation in the northern Andes. Geology, 47(1), 23-26.

Russo, R. M., \& Silver, P. G. (1994). Trench-parallel flow beneath the nazca plate from seismic anisotropy. Science, 263(5150), 1105-1111.

Samowitz, I. R., \& Forsyth, D. W. (1981). Double seismic zone beneath the Mariana Island Arc. Journal of Geophysical Research, 86(B8), 7013-7021.

Sandiford, M., Coblentz, D., \& Schellart, W. P. (2005). Evaluating slab-plate coupling in the Indo-Australian Plate. Geology, $33(2), 113$.

Sandiford, D., \& Moresi, L. (2019). Improving subduction interface implementation in dynamic numerical models. Solid Earth, 10(3), 969-985.

Sandiford, D., Moresi, L., Sandiford, M., \& Yang, T. (2019). Geometric controls on flat slab seismicity. Earth and Planetary Science Letters, $527,115,787$.

Schellart, W. P. (2004). Quantifying the net slab pull force as a driving mechanism for plate tectonics. Geophysical Research Letters, 31(7), L07611. https://doi.org/10.1029/2004GL019528

Schellart, W. P. (2017). Andean mountain building and magmatic arc migration driven by subduction-induced whole mantle flow. Nature communications, 8(1), 2010.

Seno, T., \& Yamanaka, Y. (2013). Double seismic zones, compressional deep trench-outer rise events, and superplumes, Subduction top to bottom (pp. 347-355). Washington, DC: American Geophysical Union.

Shillington, D. J., Bécel, A., Nedimović, M. R., Kuehn, H., Webb, S. C., Abers, G. A., et al. (2015). Link between plate fabric, hydration and subduction zone seismicity in Alaska. Nature Geoscience, 8(12), 961.

Sleep, N. H. (1979). The double seismic zone in downgoing slabs and the viscosity of the mesosphere. Journal of Geophysical Research, 84(B9), 4565.

Sleep, N. H. (2012). Constraint on the recurrence of great outer-rise earthquakes from seafloor bathymetry. Earth, Planets and Space, 64(12), 19.

Sykes, L. R., \& Sbar, M. L. (1973). Intraplate earthquakes, lithospheric stresses and the driving mechanism of plate tectonics. Nature, 245(5424), 298-302.

Tsujimori, T., Sisson, V., Liou, J., Harlow, G., \& Sorensen, S. (2006). Very-low-temperature record of the subduction process: A review of worldwide lawsonite eclogites. Lithos, 92(3-4), 609-624.

Tsukahara, H. (1980). Physical conditions for double seismic planes of the deep seismic zone. Journal of Physics of the Earth, 28(1), $1-15$.

Turcotte, D. L., \& Oxburgh, E. R. (1967). Finite amplitude convective cells and continental drift. Journal of Fluid Mechanics, 28(1), 29-42.

van Hunen, J., van den Berg, A. P., \& Vlaar, N. J. (2004). Various mechanisms to induce present-day shallow flat subduction and implications for the younger Earth: A numerical parameter study. Physics of the Earth and Planetary Interiors, 146(1-2), 179-194.

van Summeren, J., Conrad, C. P., \& Lithgow-Bertelloni, C. (2012). The importance of slab pull and a global asthenosphere to plate motions. Geochemistry, Geophysics, Geosystems, 13, Q0AK03. https://doi.org/10.1029/2011GC003873

Vassiliou, M. S., Hager, B. H., \& Raefsky, A. (1984). The distribution of earthquakes with depth and stress in subducting slabs. Journal of Geodynamics, 1(1), 11-28. 
Wagner, L. S., \& Okal, E. A. (2019). The Pucallpa Nest and its constraints on the geometry of the Peruvian Flat Slab. Tectonophysics, 762, 97-108.

Wang, K. (2002). Unbending combined with dehydration embrittlement as a cause for double and triple seismic zones. Geophysical Research Letters, 29(18), 36-1-36-4.

Yang, T., Gurnis, M., \& Zhan, Z. (2017). Trench motion-controlled slab morphology and stress variations: Implications for the isolated 2015 Bonin Islands deep earthquake. Geophysical Research Letters, 44, 6641-6650. https://doi.org/10.1002/2017GL073989

Yang, T., Moresi, L., Gurnis, M., Liu, S., Sandiford, D., Williams, S., \& Capitanio, F. A. (2019). Contrasted East Asia and South America tectonics driven by deep mantle flow. Earth and Planetary Science Letters, 517, 106-116. 


\section{University Library}

\section{- M M N E R VA A gateway to Melbourne's research publications}

Minerva Access is the Institutional Repository of The University of Melbourne

Author/s:

Sandiford, D;Moresi, LM;Sandiford, M;Farrington, R;Yang, T

Title:

The Fingerprints of Flexure in Slab Seismicity

Date:

2020-08-01

Citation:

Sandiford, D., Moresi, L. M., Sandiford, M., Farrington, R. \& Yang, T. (2020). The Fingerprints of Flexure in Slab Seismicity. TECTONICS, 39 (8), https://doi.org/10.1029/2019TC005894.

Persistent Link:

http://hdl.handle.net/11343/253827 